\title{
Controlling bismuth vanadate morphology and crystalline structure through optimization of microwave-assisted synthesis conditions
}

Scola Rodrigues, Bárbara; Branco, Carolyne Martins; ${ }^{a}$ Corio, Paola, ${ }^{\text {b Souza, }}$ Juliana $S^{\text {a1 }}$

${ }^{a}$ Centro de Ciências Naturais e Humanas, Universidade Federal do ABC, 09210-580, Santo André, SP, Brazil.

'Instituto de Química, Universidade de São Paulo, C.P. 26077, 05513-970 São Paulo, SP, Brazil

\footnotetext{
${ }^{1}$ Corresponding author: juliana.souza@ufabc.edu.br
} 


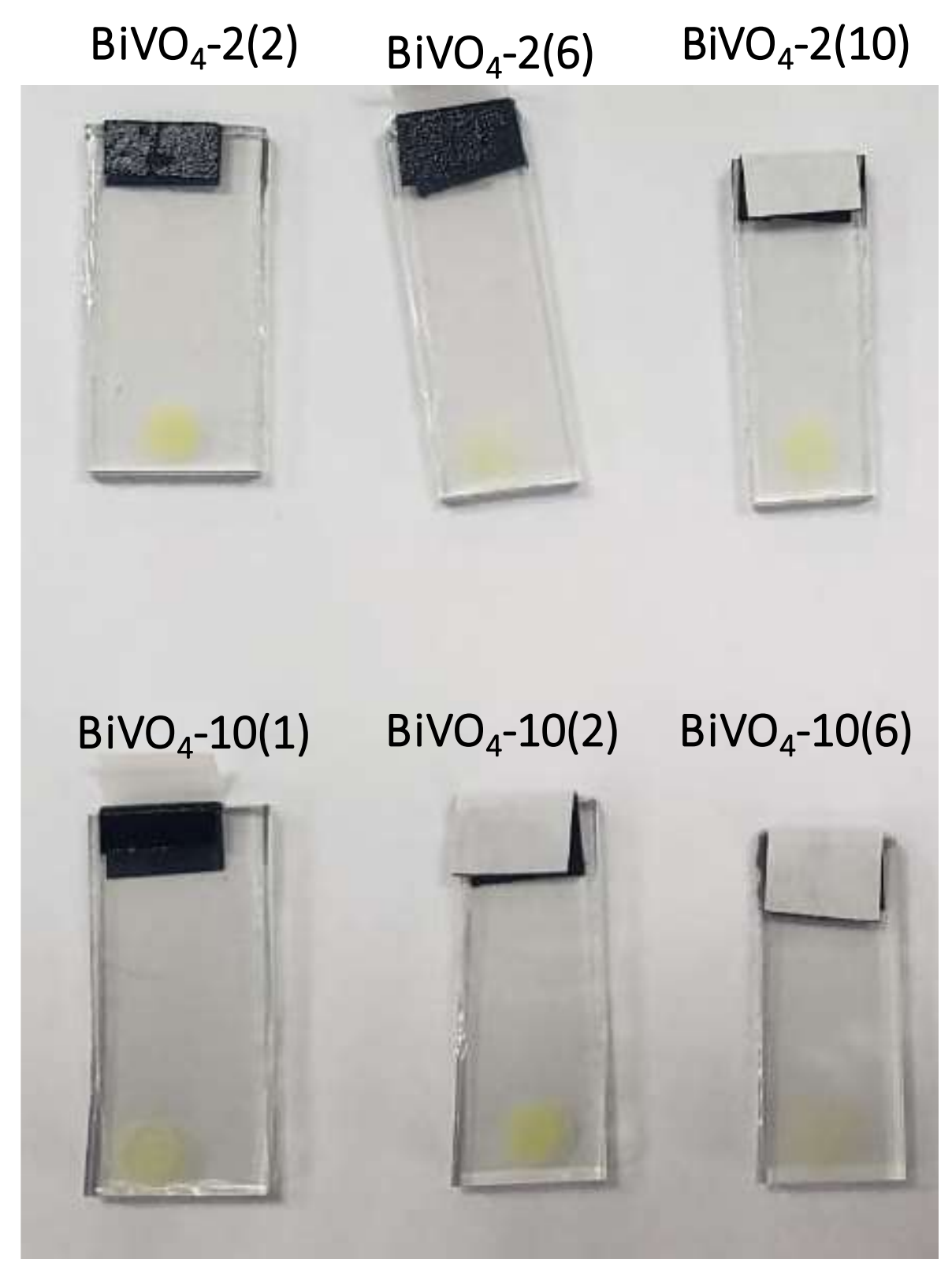

Figure S1. Images of the films used on the electrochemical experiments. 


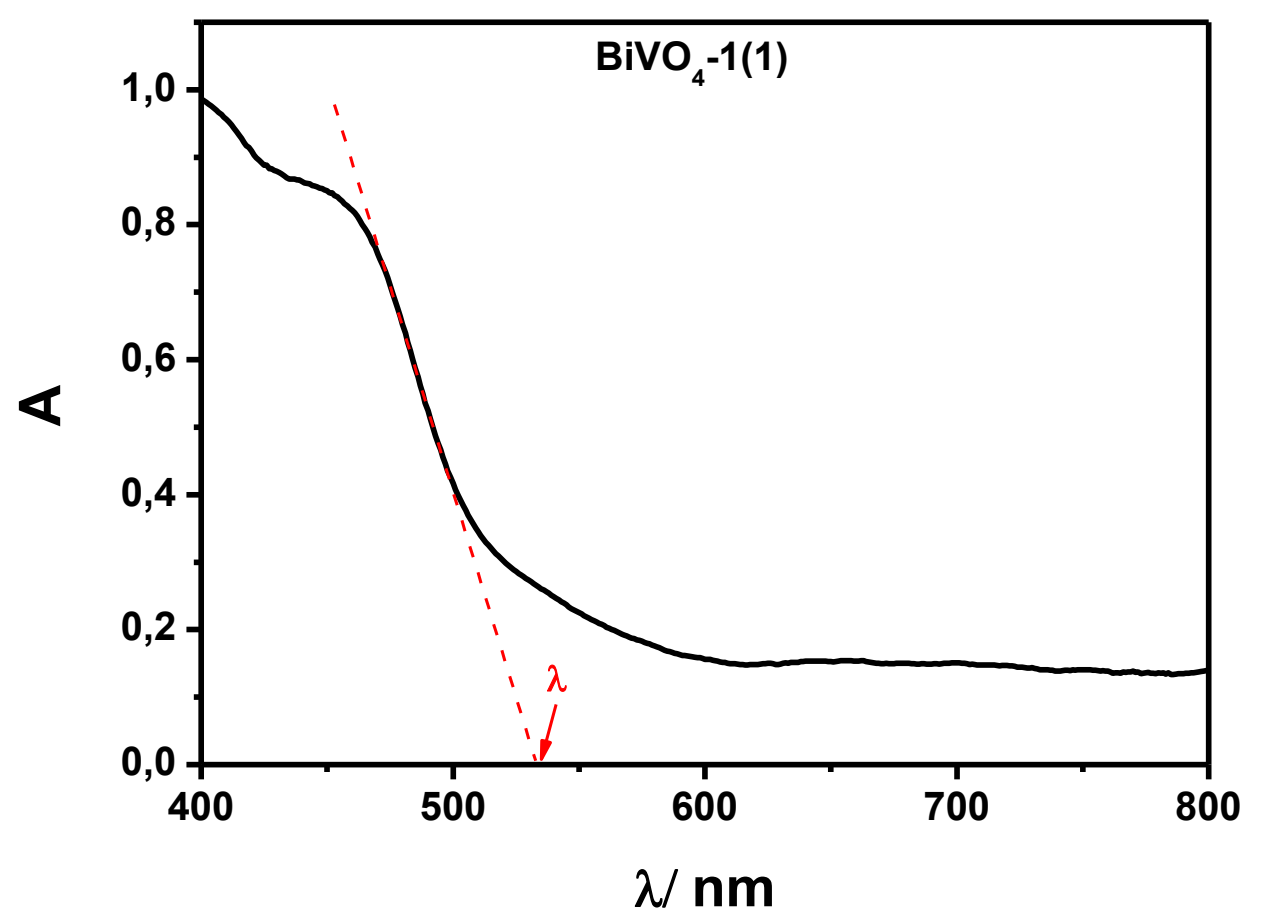

Figure S2. The diffuse reflectance spectrum of $\mathrm{BiVO}_{4}-1(1)$, where the characteristic wavelength value is marked. 


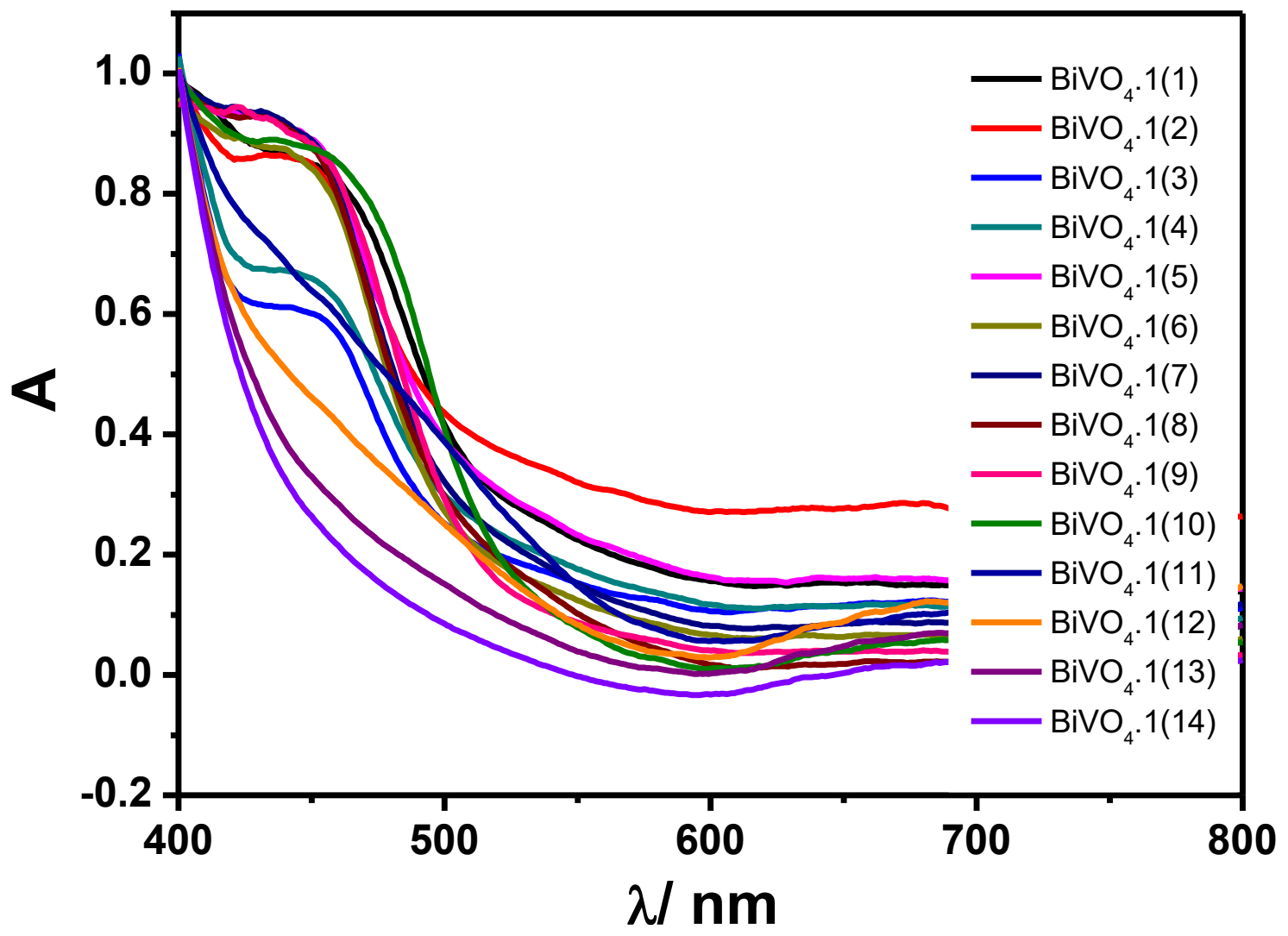

Figure S3. Diffuse reflectance spectrum of $\mathrm{BiVO}_{4}-1$ (1-14). 


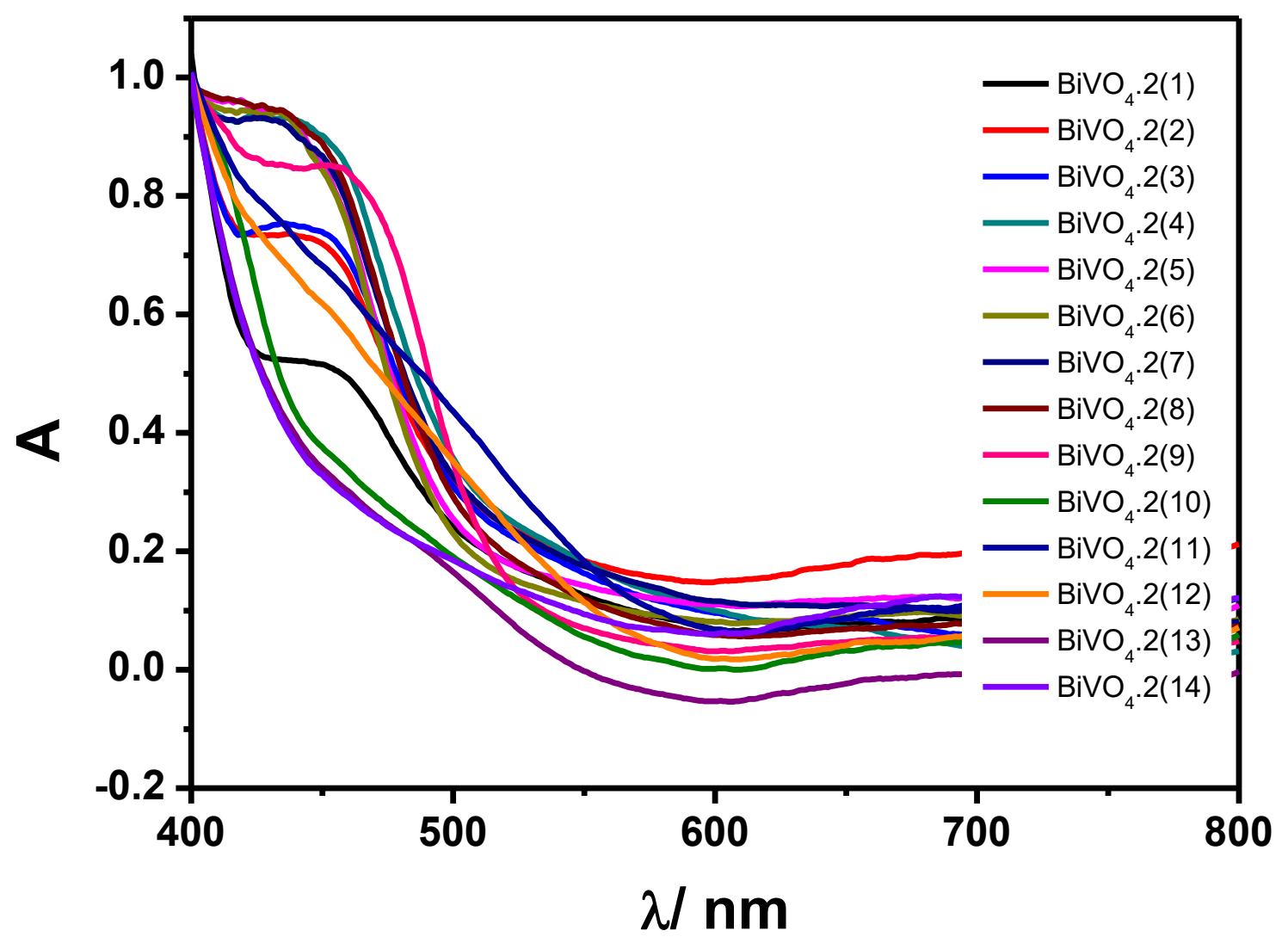

Figure S4. Diffuse reflectance spectrum of $\mathrm{BiVO}_{4}-2(1-14)$. 


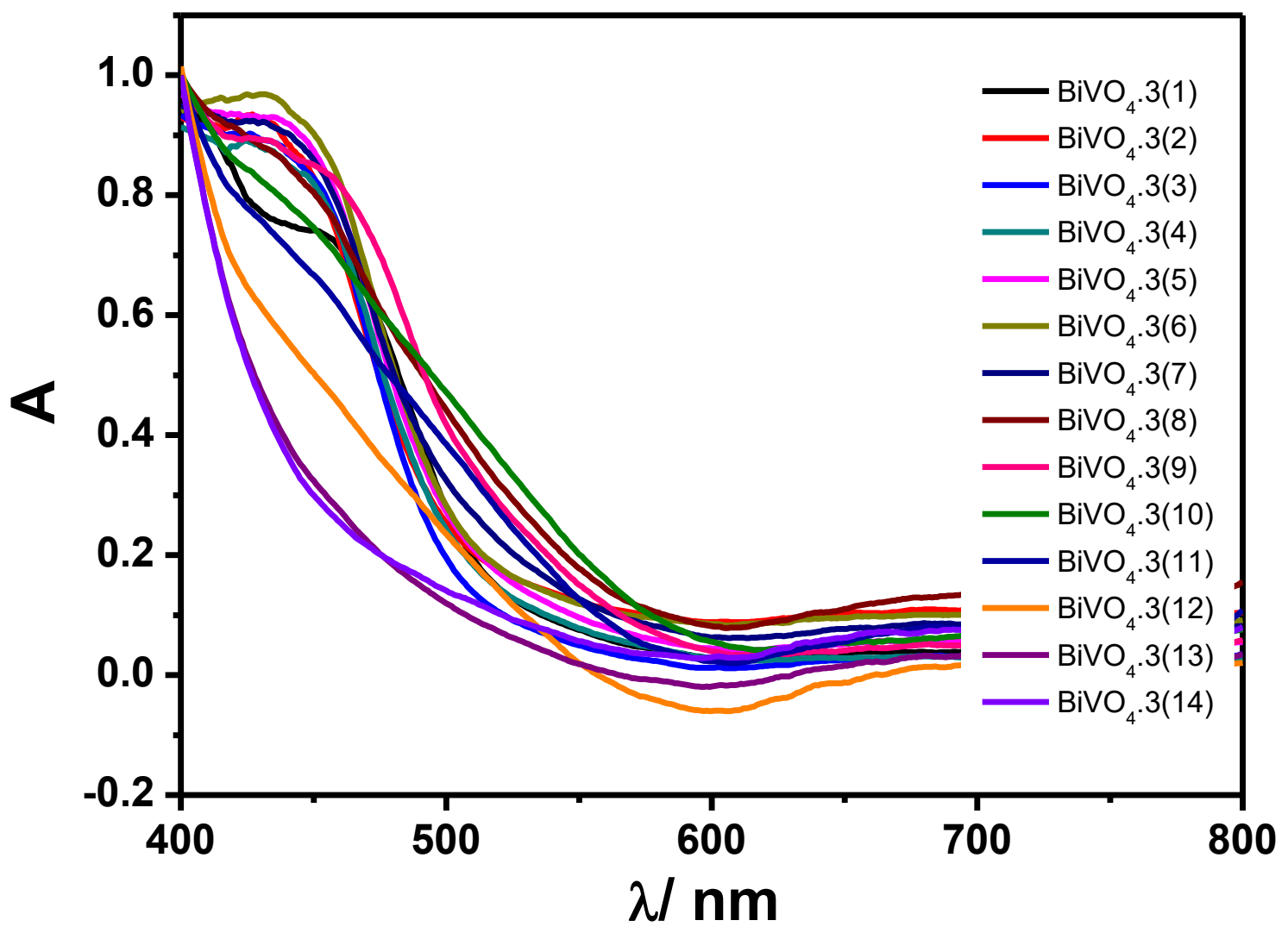

Figure S5. Diffuse reflectance spectrum of $\mathrm{BiVO}_{4}-3(1-14)$. 


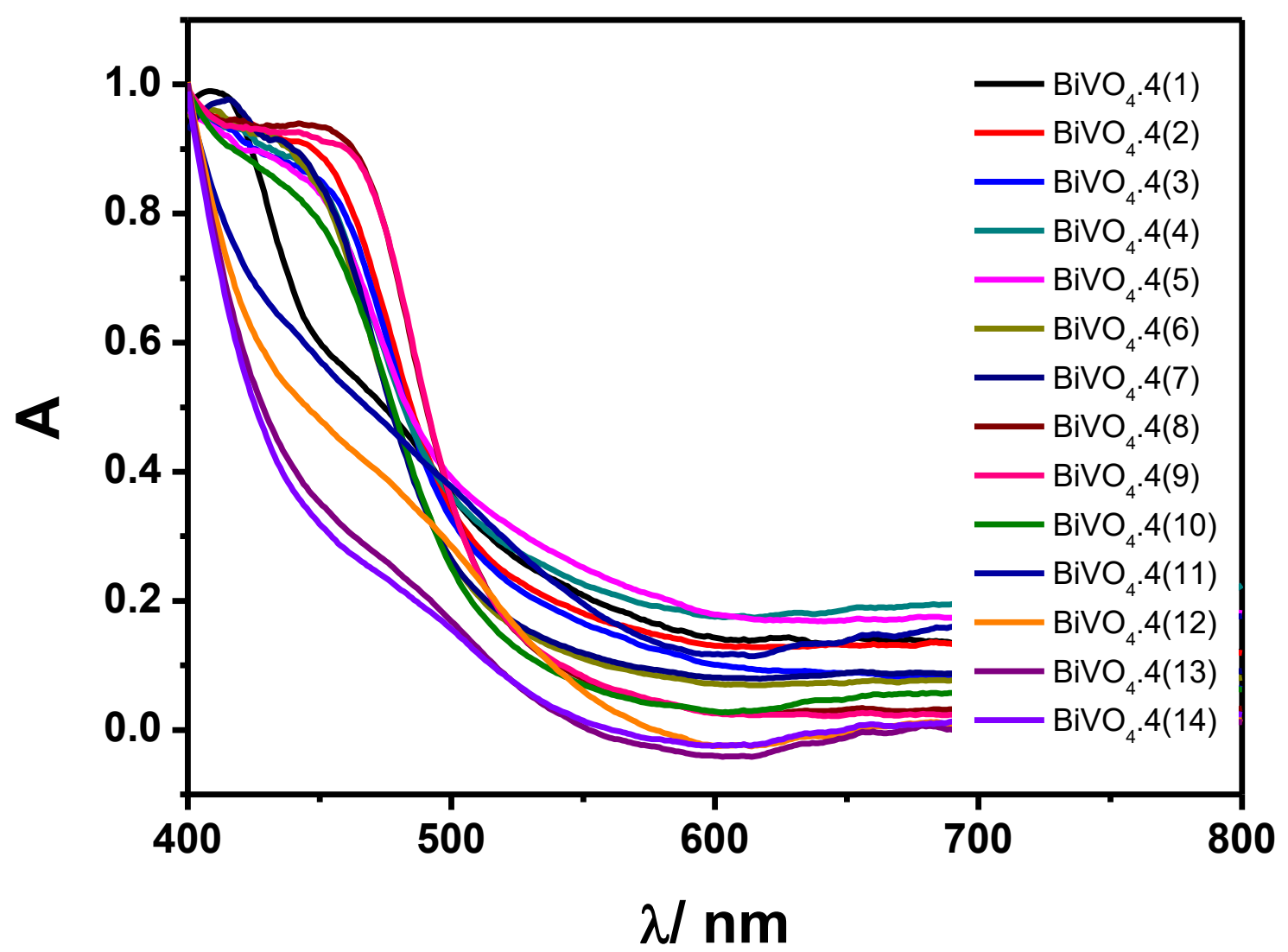

Figure S6. Diffuse reflectance spectrum of $\mathrm{BiVO}_{4}-4(1-14)$. 


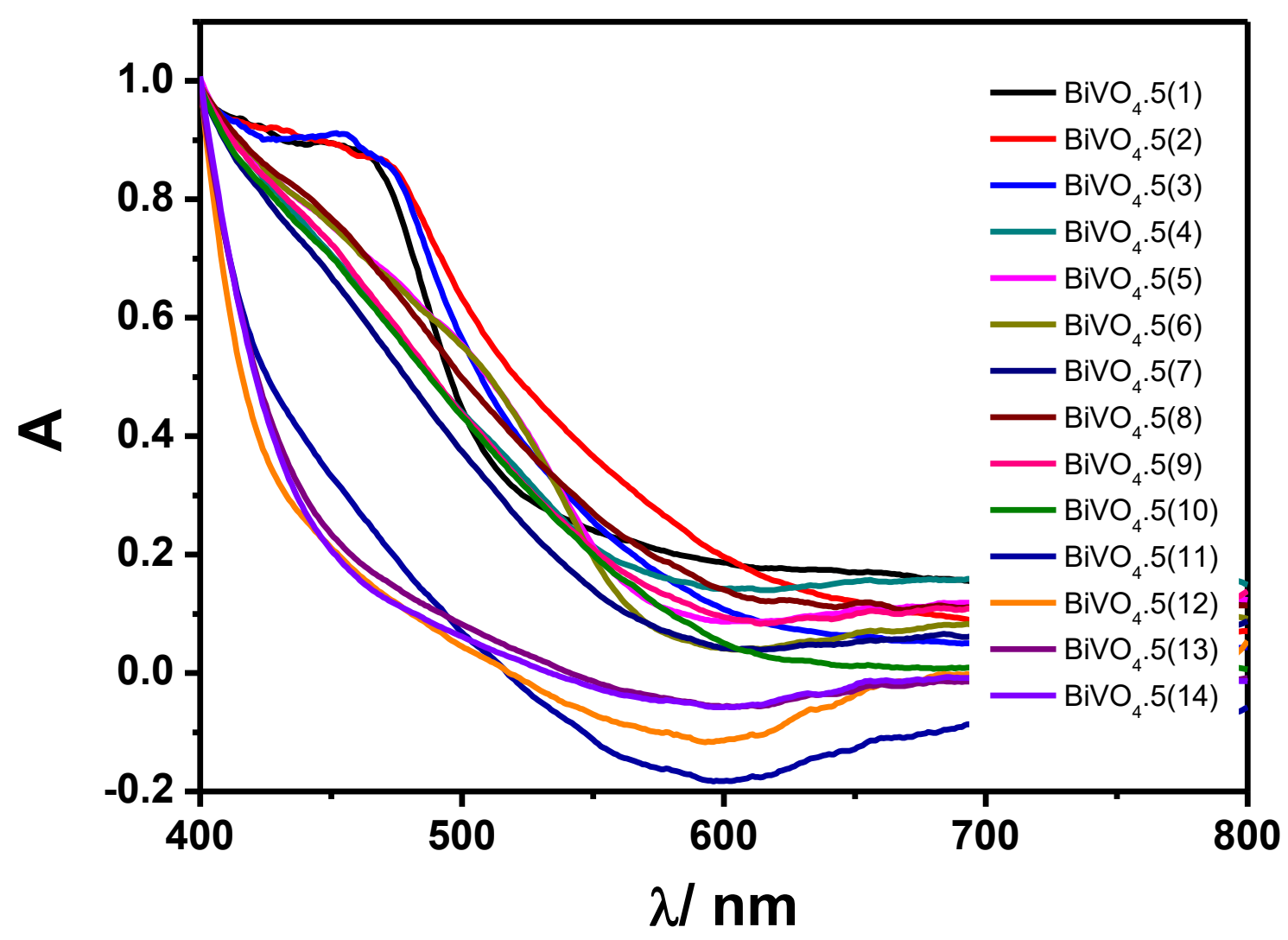

Figure S7. Diffuse reflectance spectrum of $\mathrm{BiVO}_{4}-5(1-14)$. 


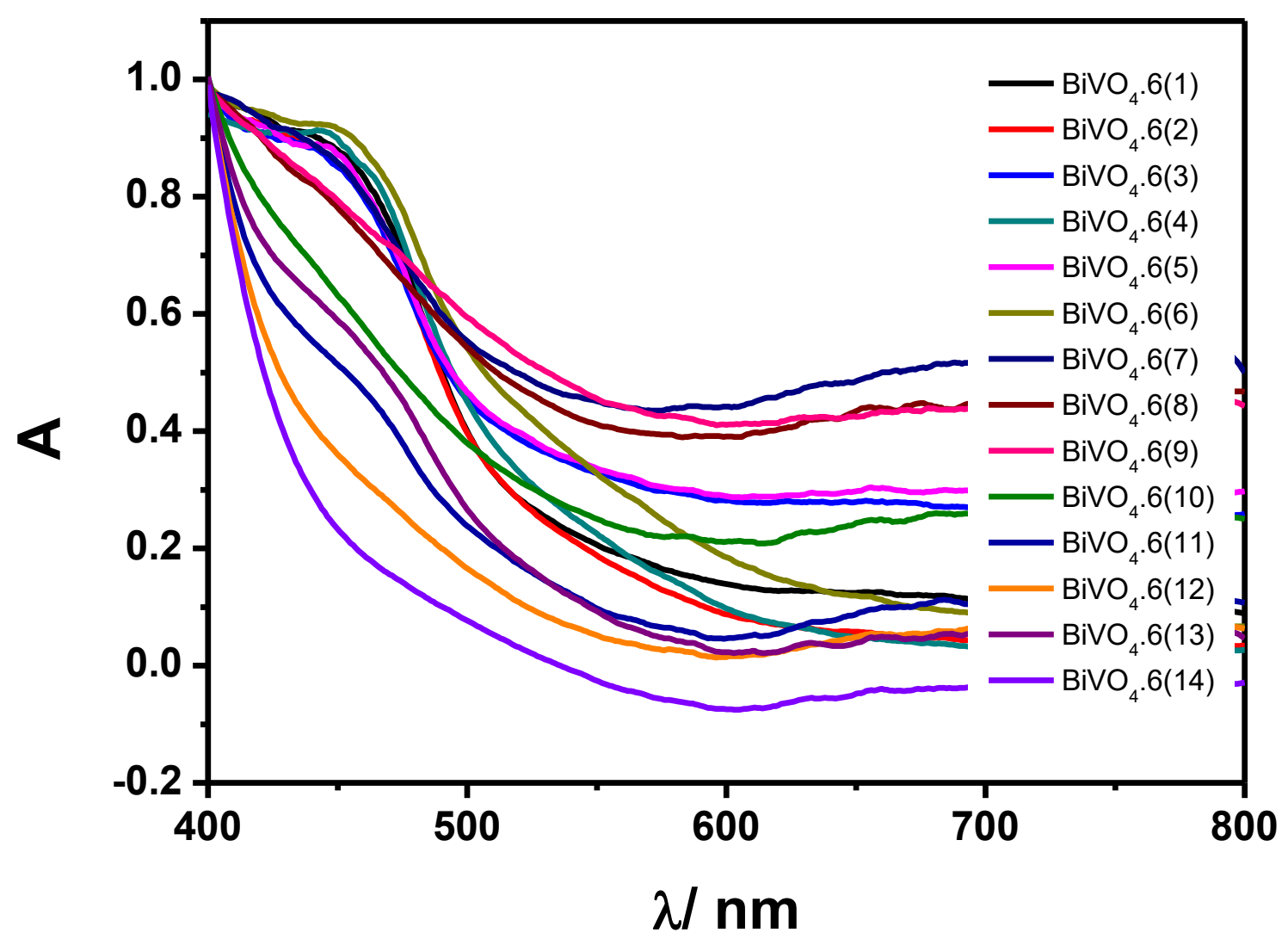

Figure S8. Diffuse reflectance spectrum of $\mathrm{BiVO}_{4}-6(1-14)$. 


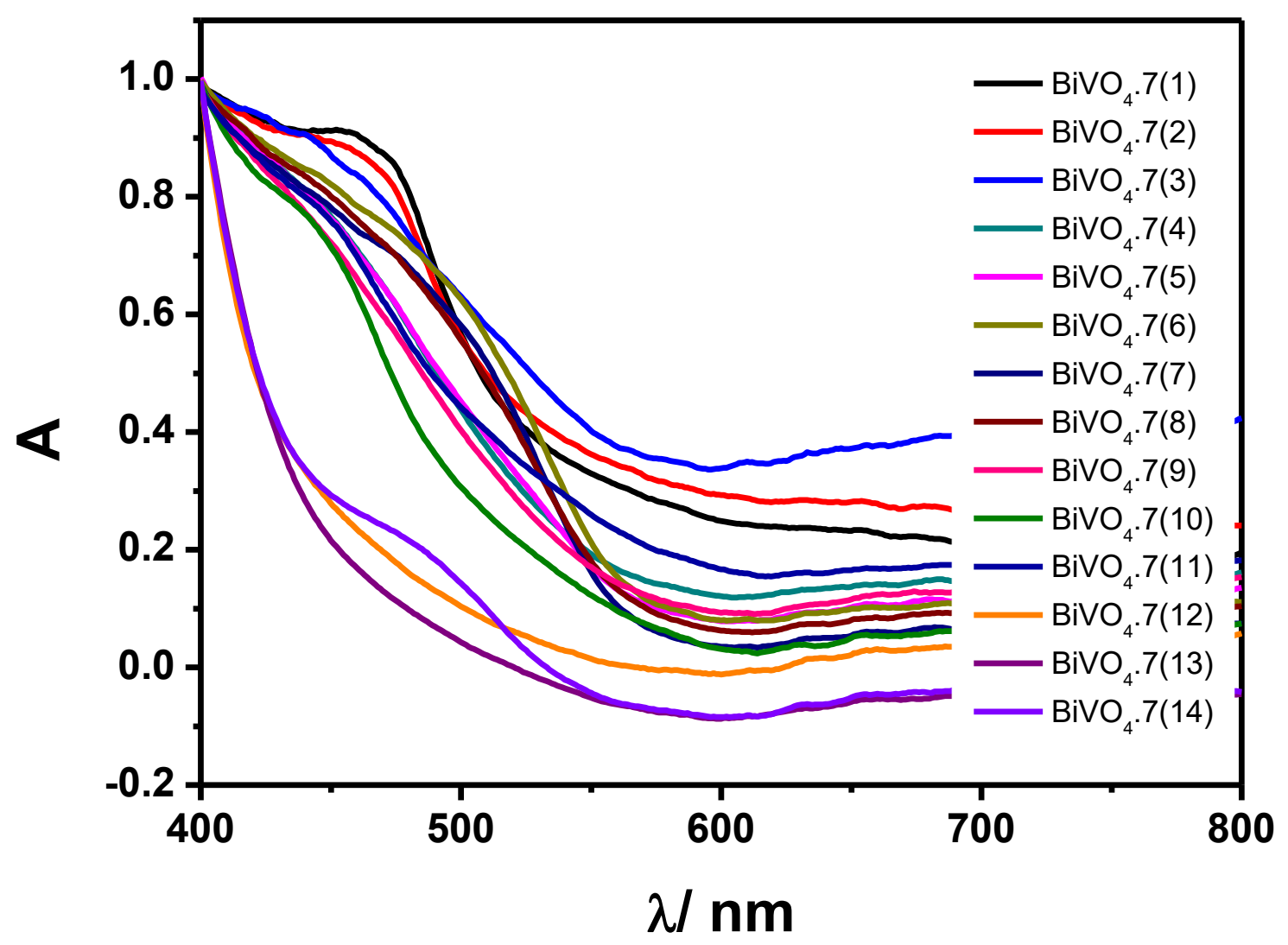

Figure S9. Diffuse reflectance spectrum of $\mathrm{BiVO}_{4}-7(1-14)$. 


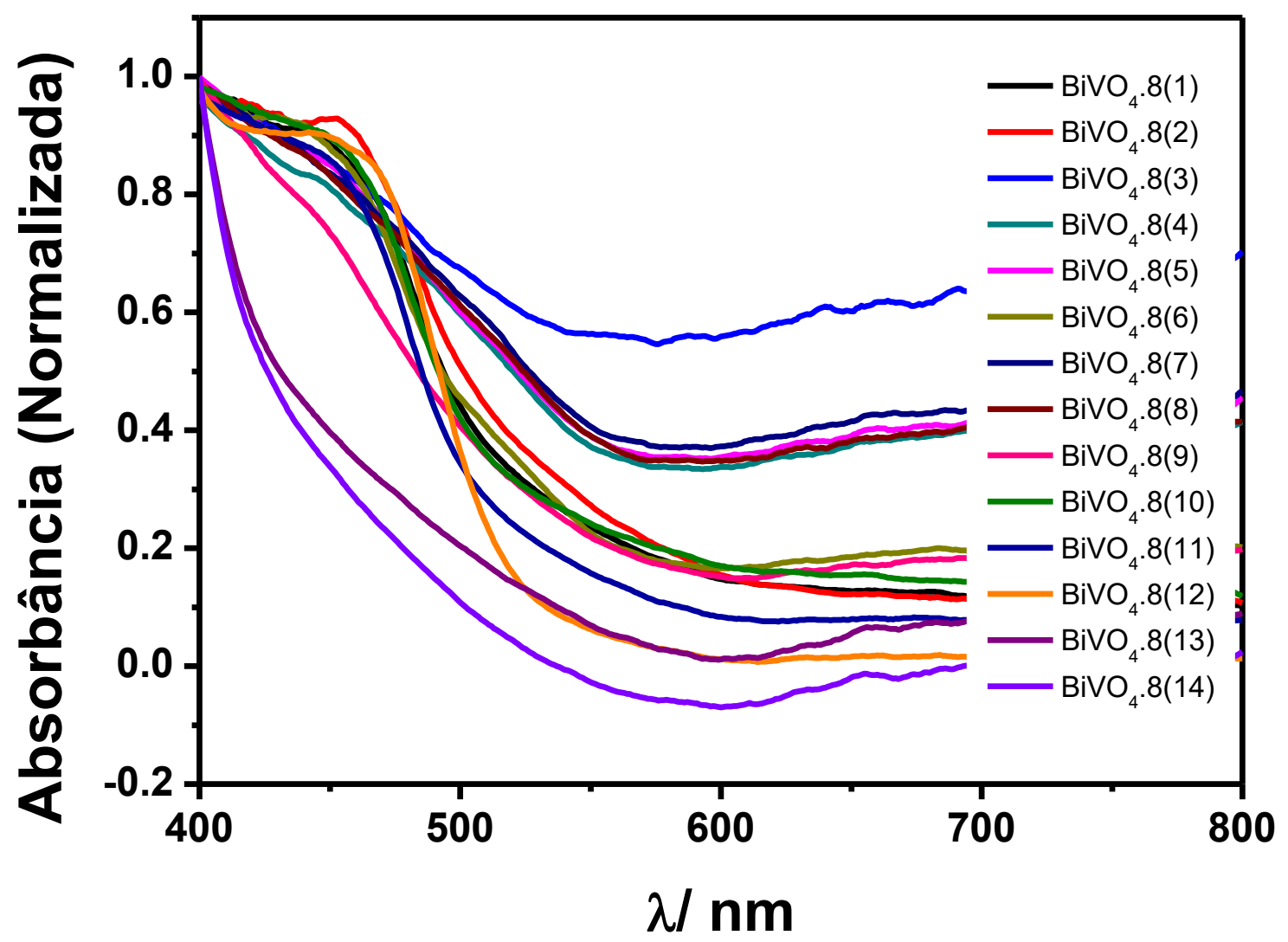

Figure S10. Diffuse reflectance spectrum of $\mathrm{BiVO}_{4}-8(1-14)$. 


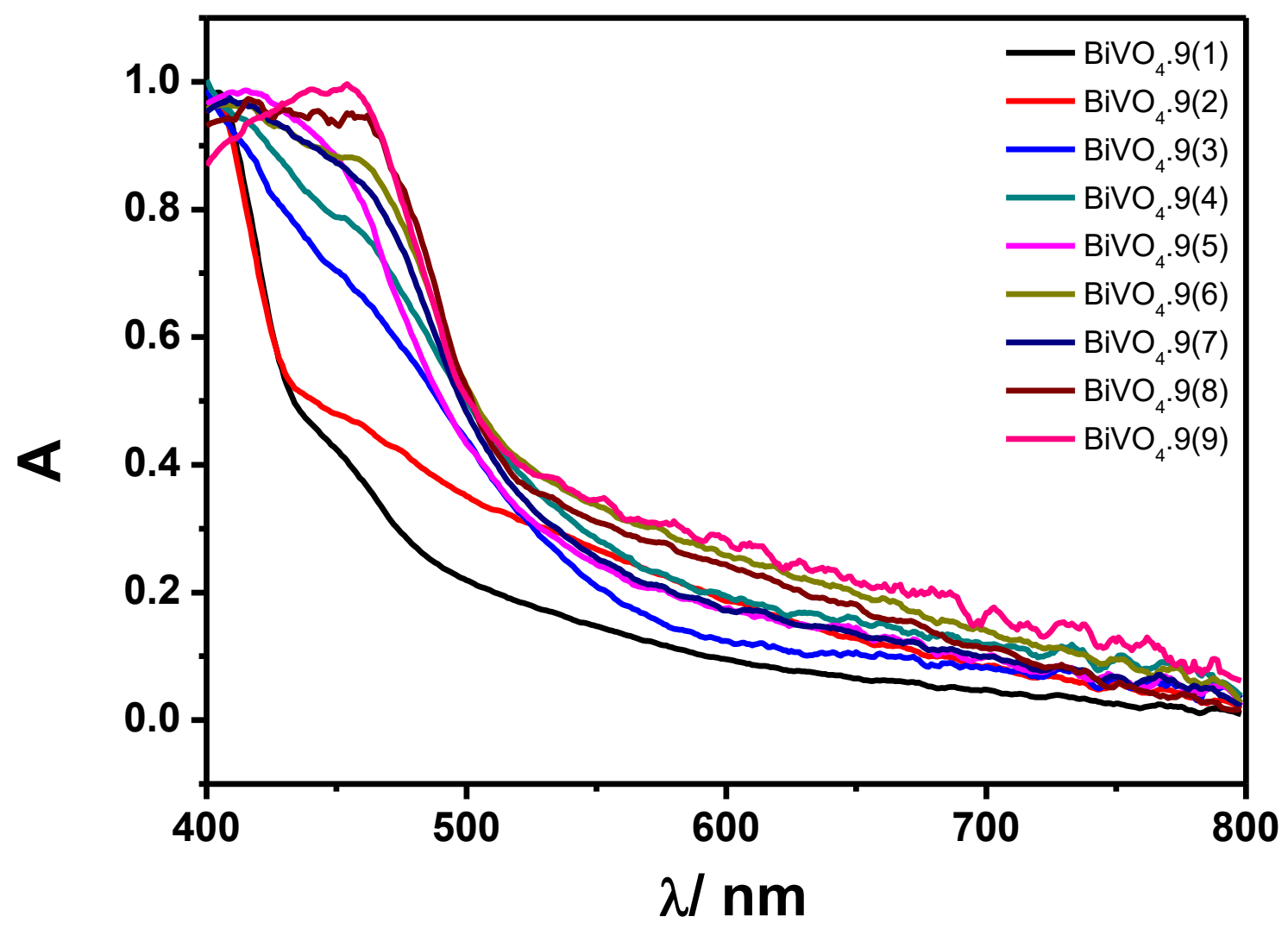

Figure S11. Diffuse reflectance spectrum of $\mathrm{BiVO}_{4}-9(1-9)$. 


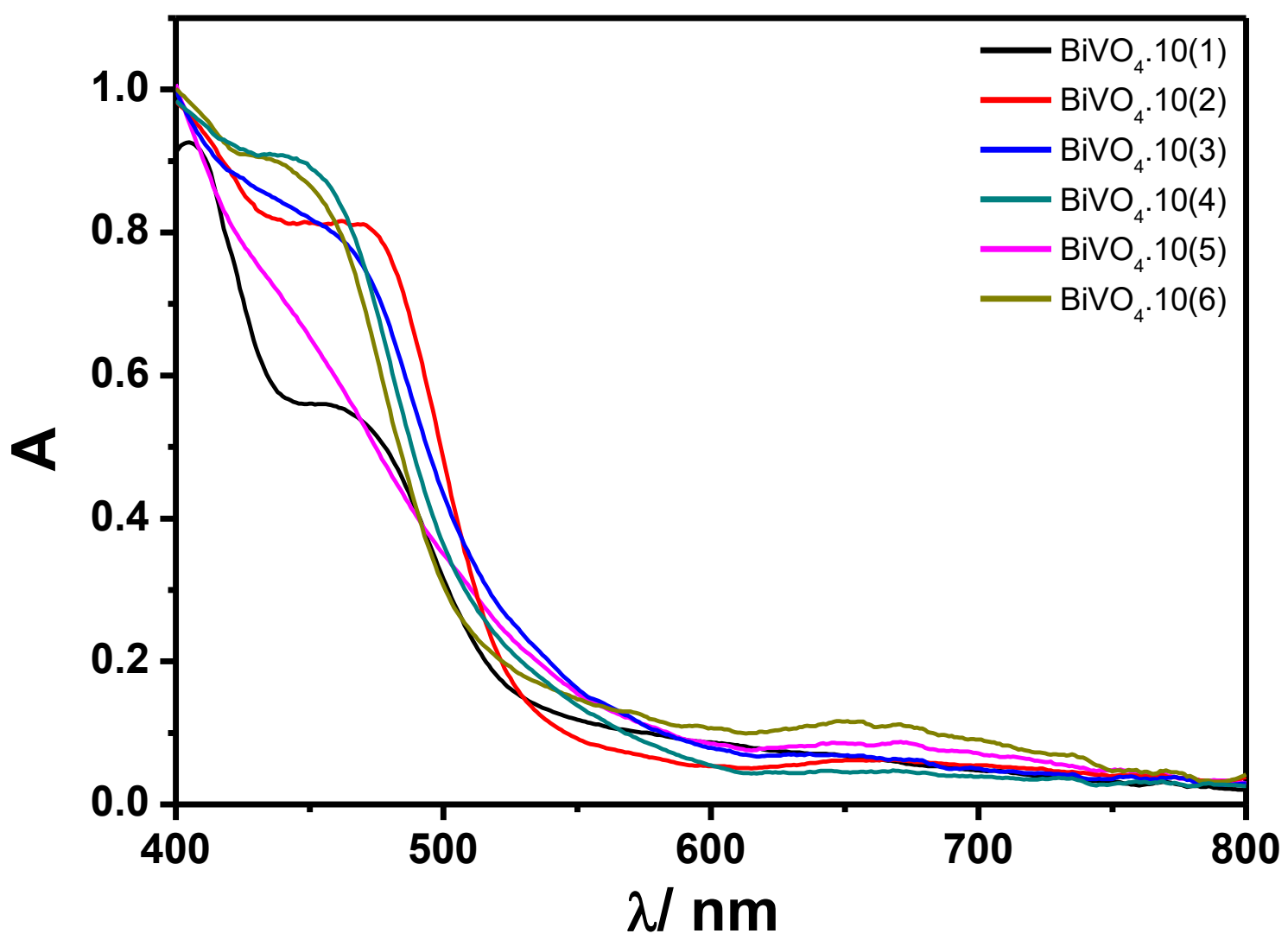

Figure S12. Diffuse reflectance spectrum of $\mathrm{BiVO}_{4}-10(1-6)$. 


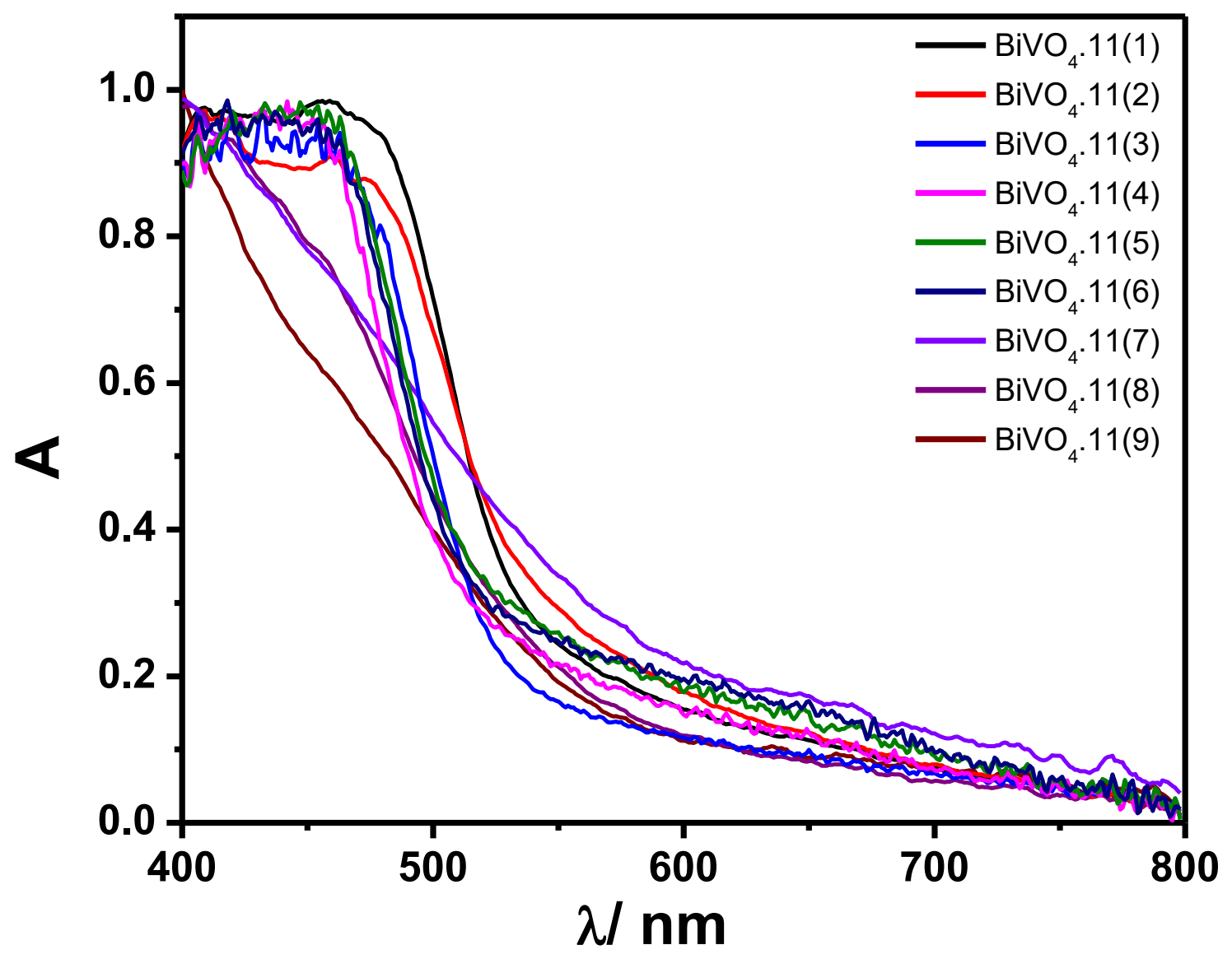

Figure S13. Diffuse reflectance spectrum of $\mathrm{BiVO}_{4}-11(1-9)$. 


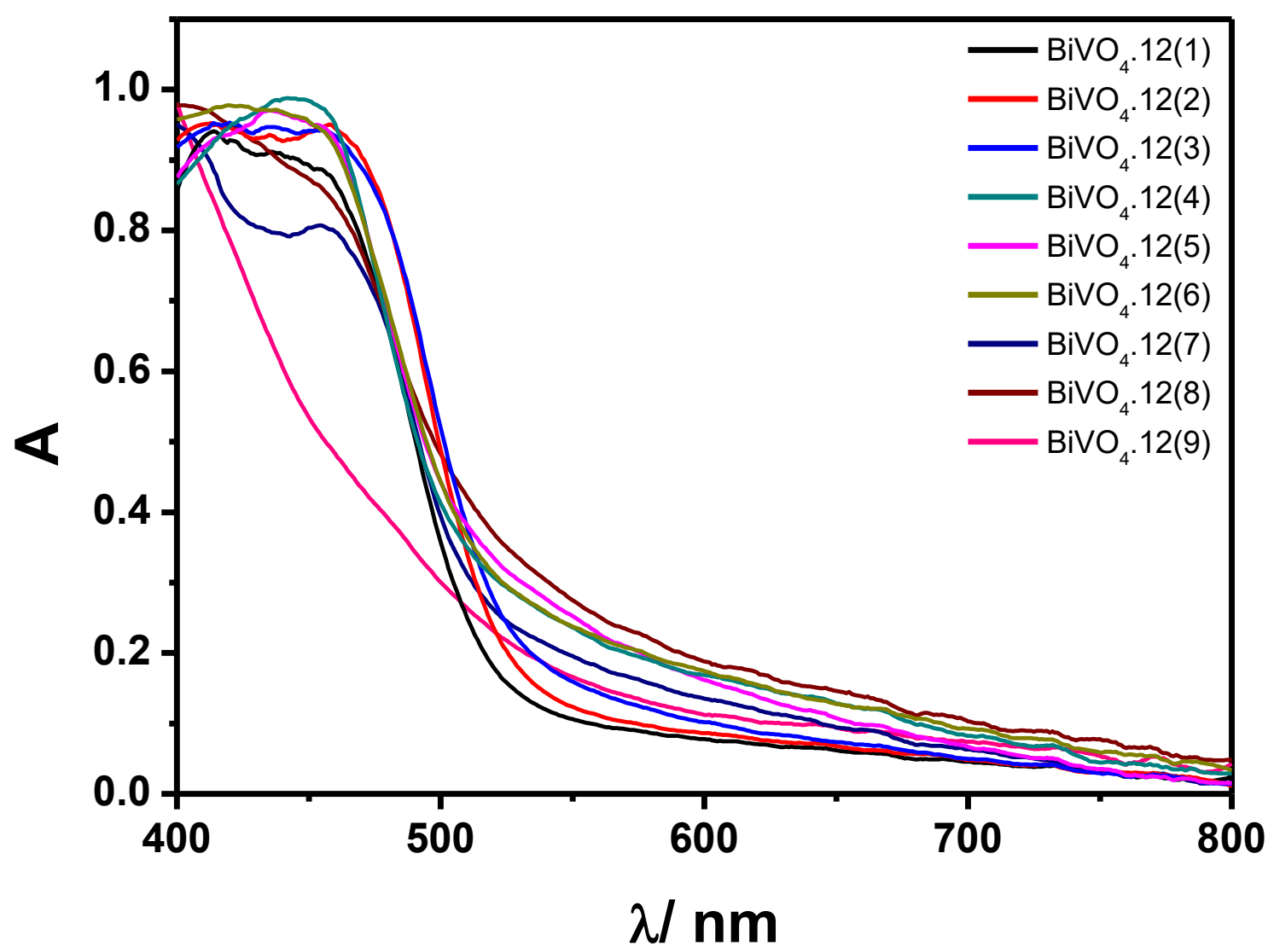

Figure S14. Diffuse reflectance spectrum of $\mathrm{BiVO}_{4}-12(1-9)$. 


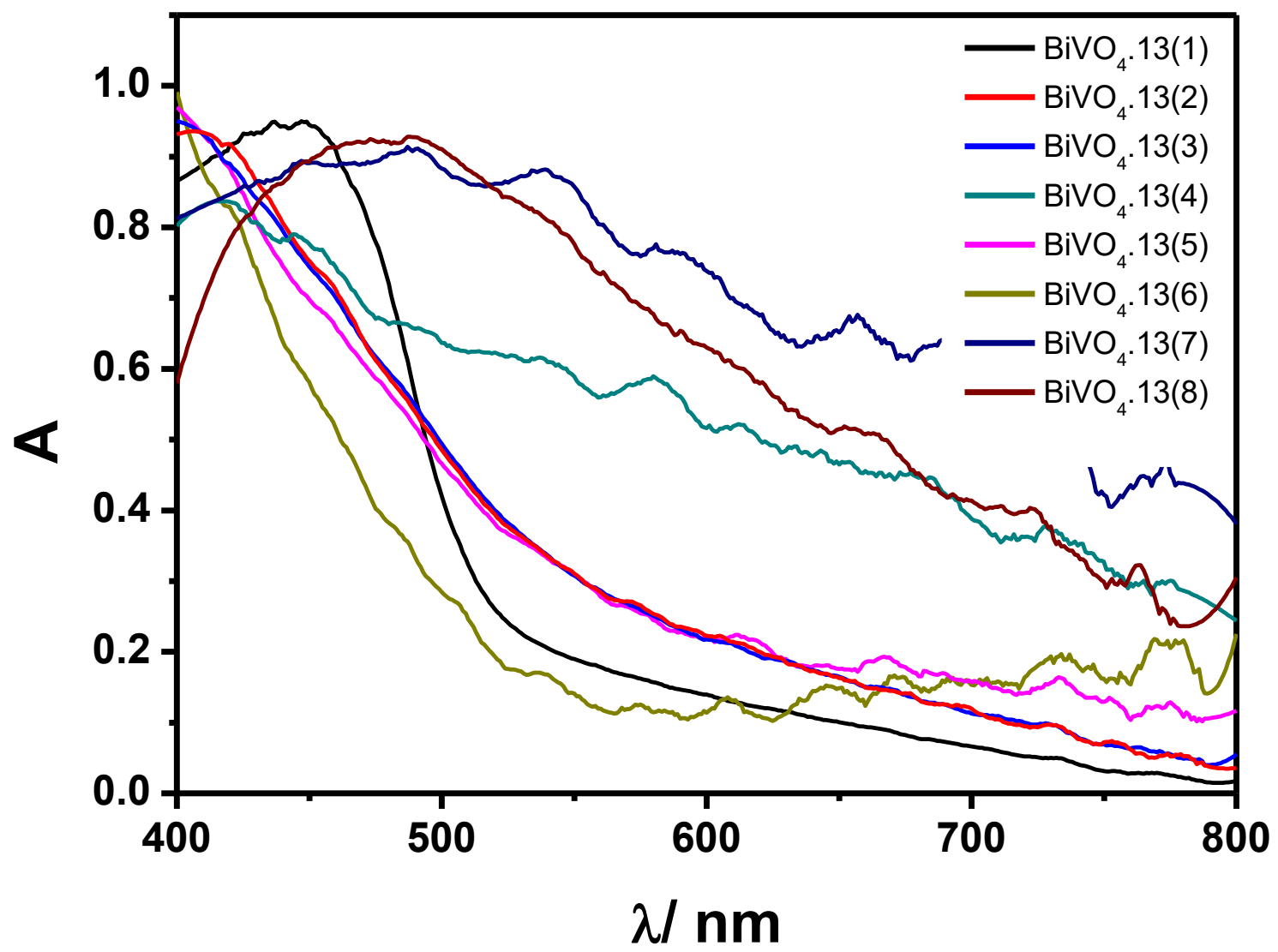

Figure S15. Diffuse reflectance spectrum of $\mathrm{BiVO}_{4}-13(1-8)$. 


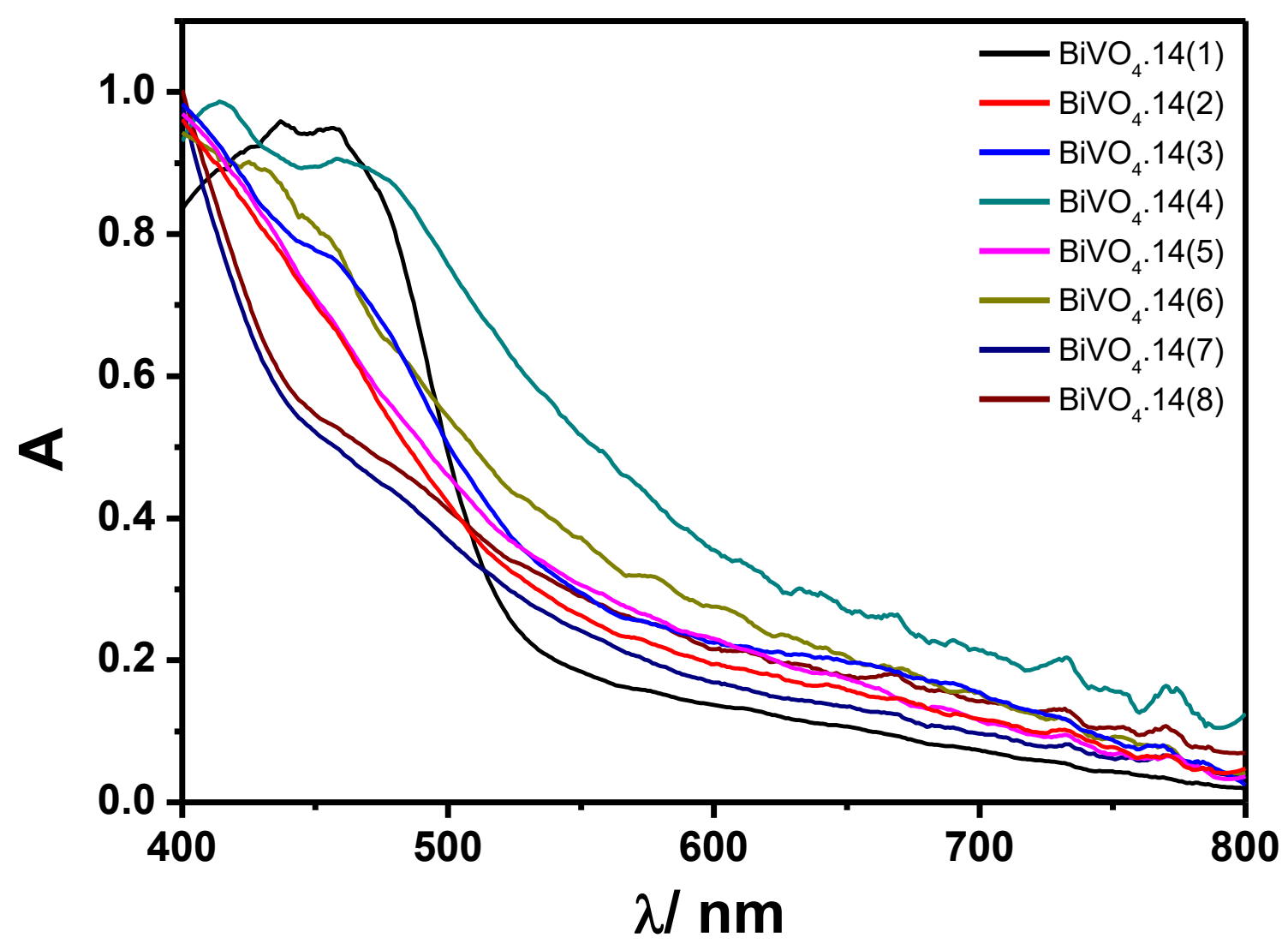

Figure S16. Diffuse reflectance spectrum of $\mathrm{BiVO}_{4}-14(1-8)$. 


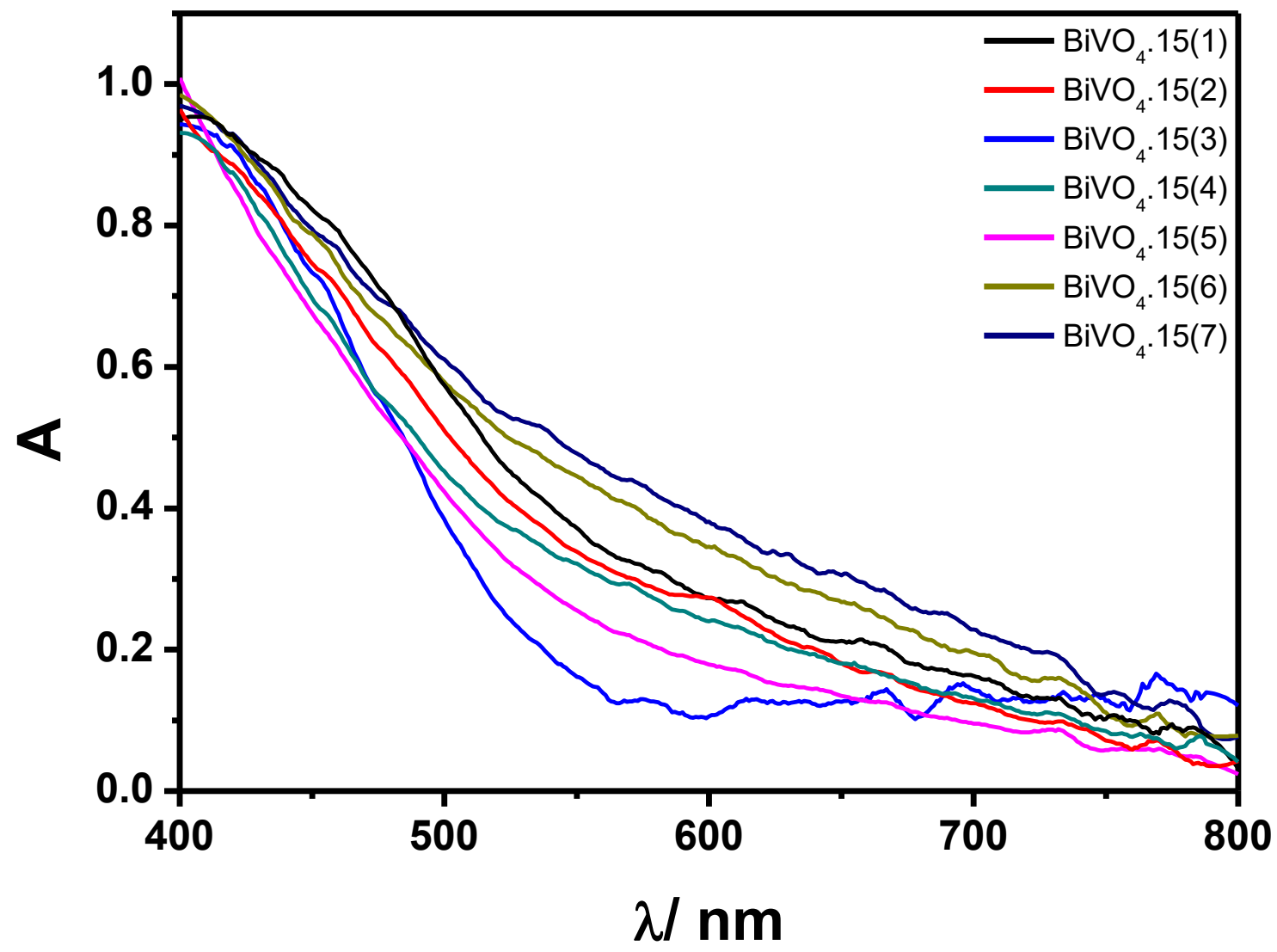

Figure S17. Diffuse reflectance spectrum of $\mathrm{BiVO}_{4}-15(1-7)$. 


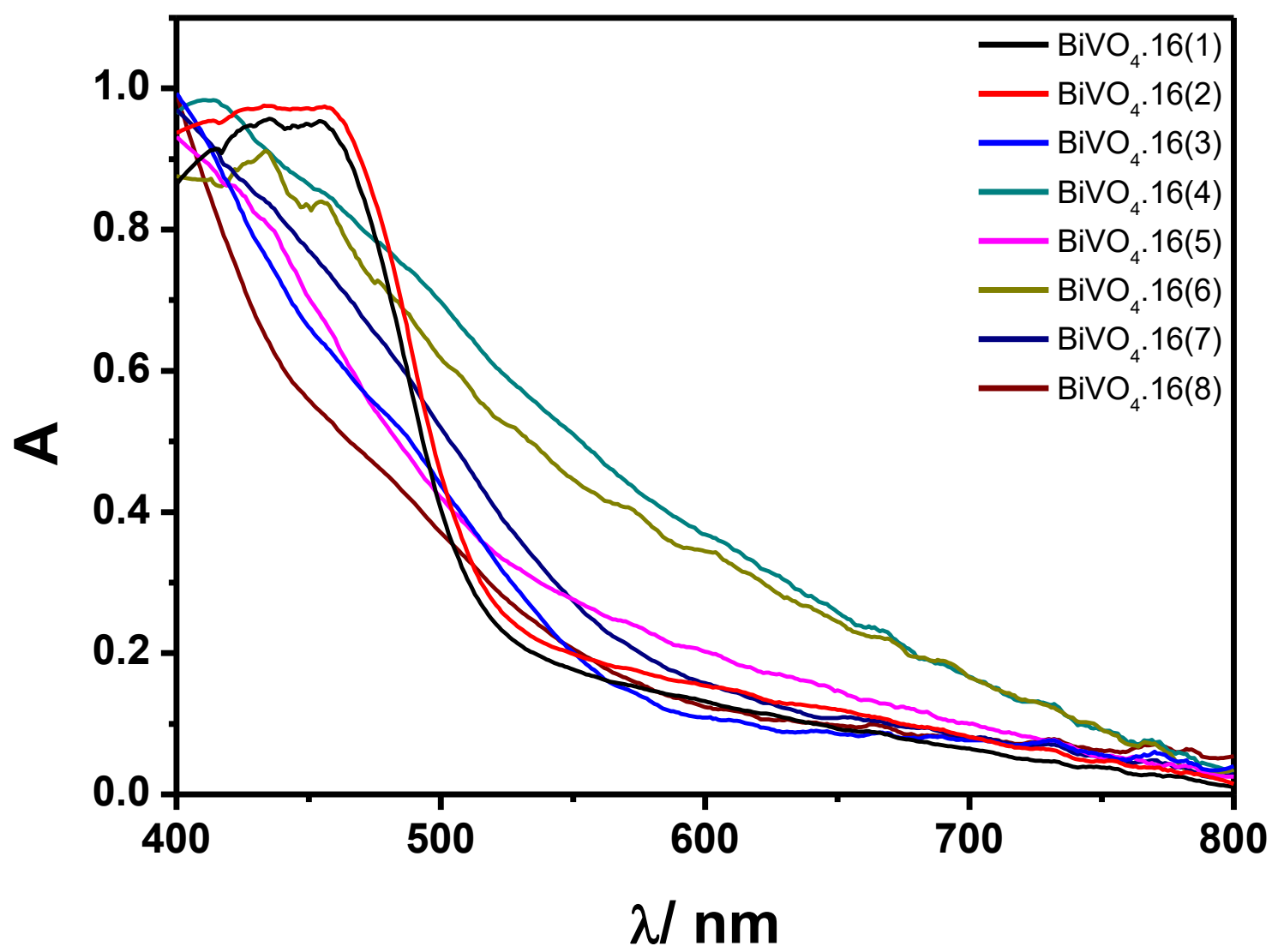

Figure S18. Diffuse reflectance spectrum of $\mathrm{BiVO}_{4}-16(1-8)$. 


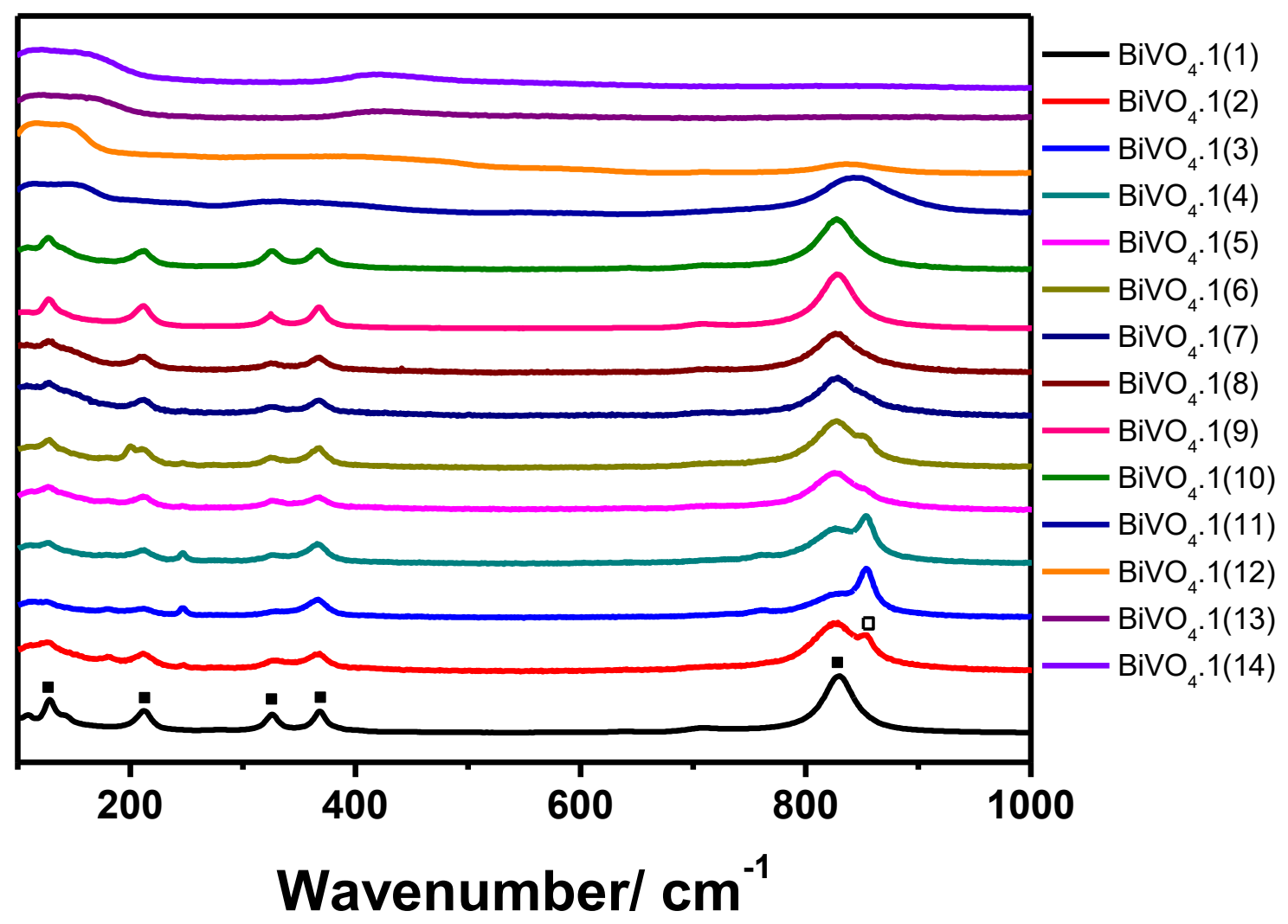

Figure S19. Raman spectra of $\mathrm{BiVO}_{4}-1(1-14)$. 


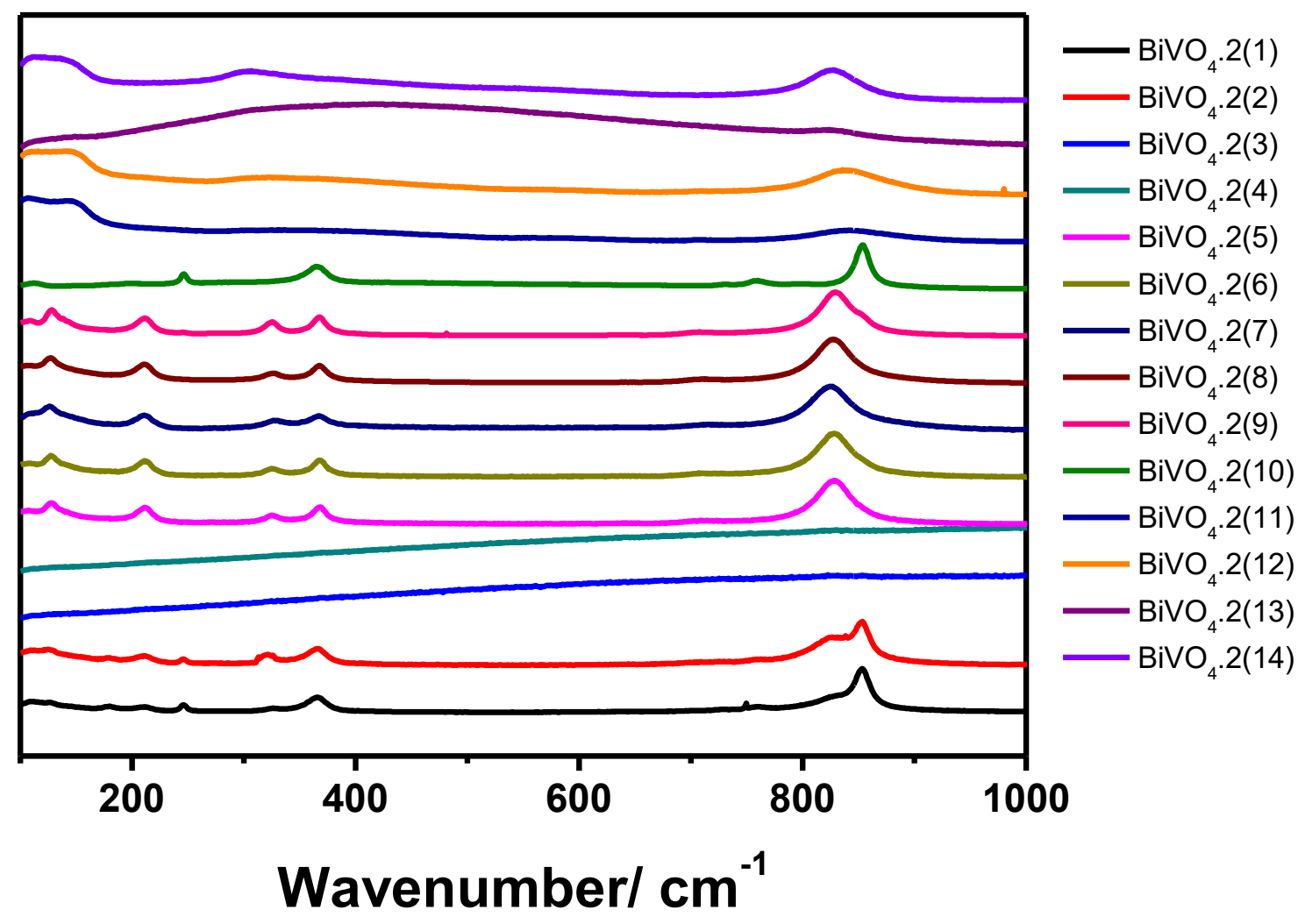

Figure S20. Raman spectra of $\mathrm{BiVO}_{4}-2(1-14)$. 


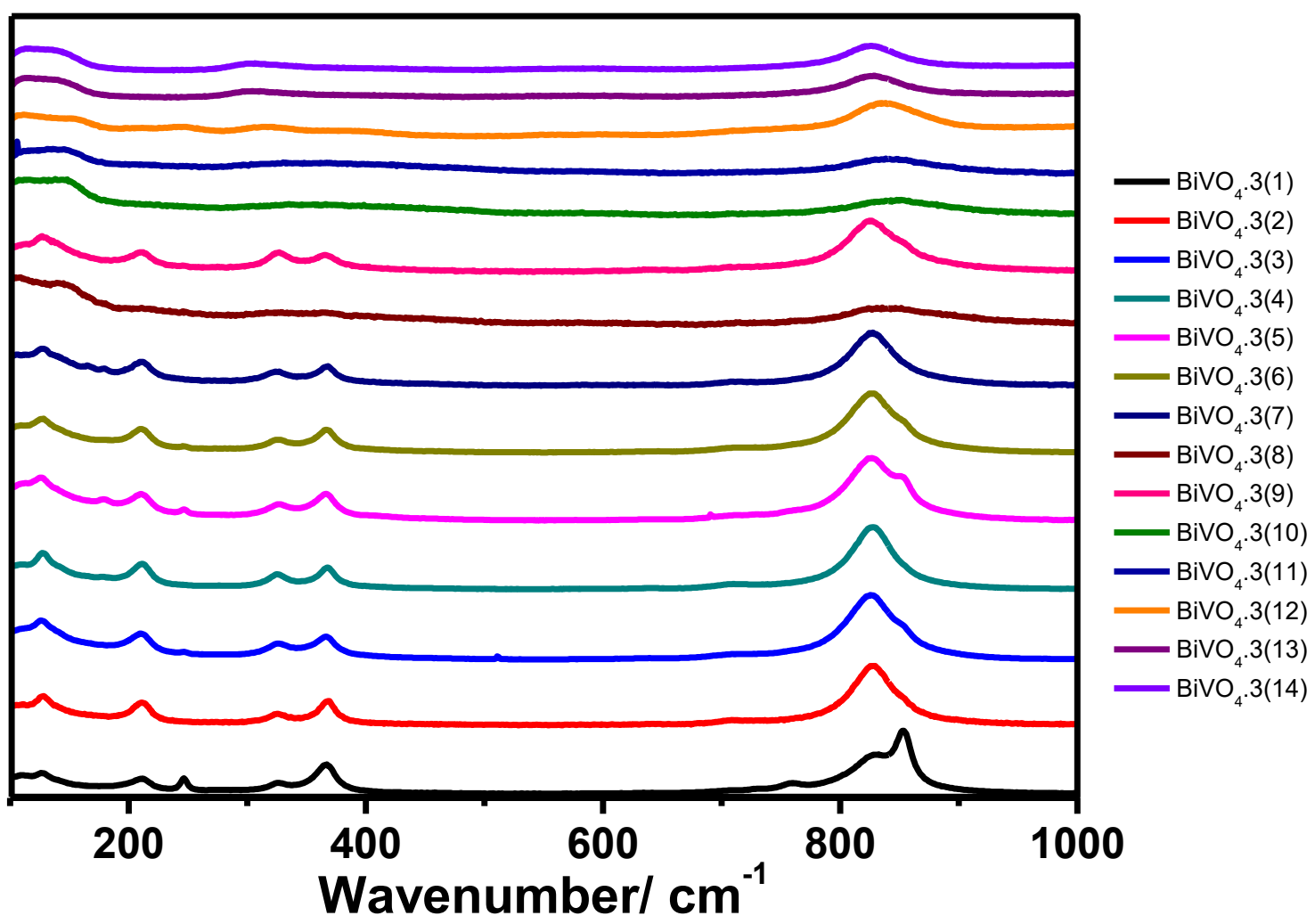

Figure S21. Raman spectra of $\mathrm{BiVO}_{4}-3(1-14)$. 


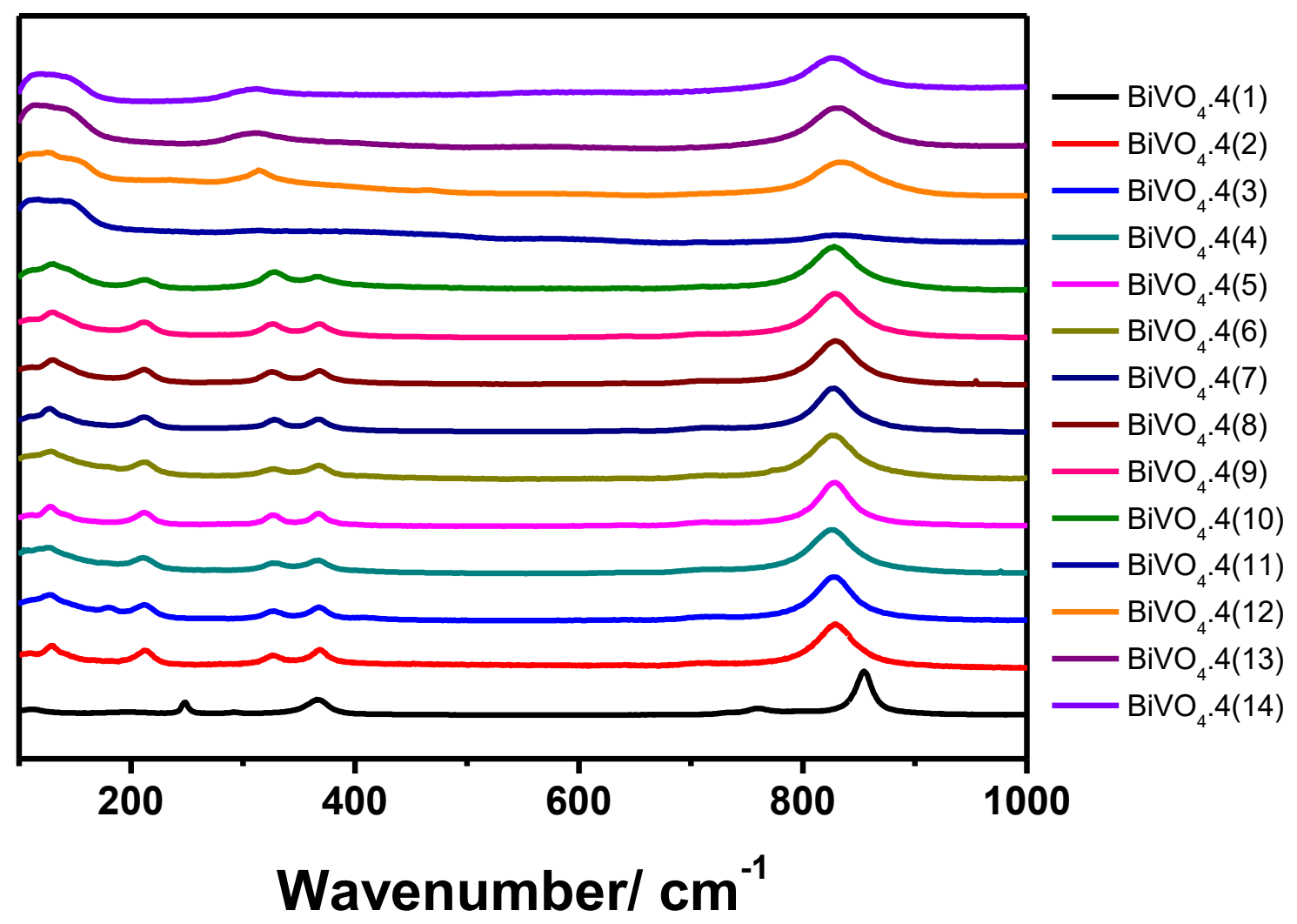

Figure S22. Raman spectra of $\mathrm{BiVO}_{4}-4(1-14)$. 


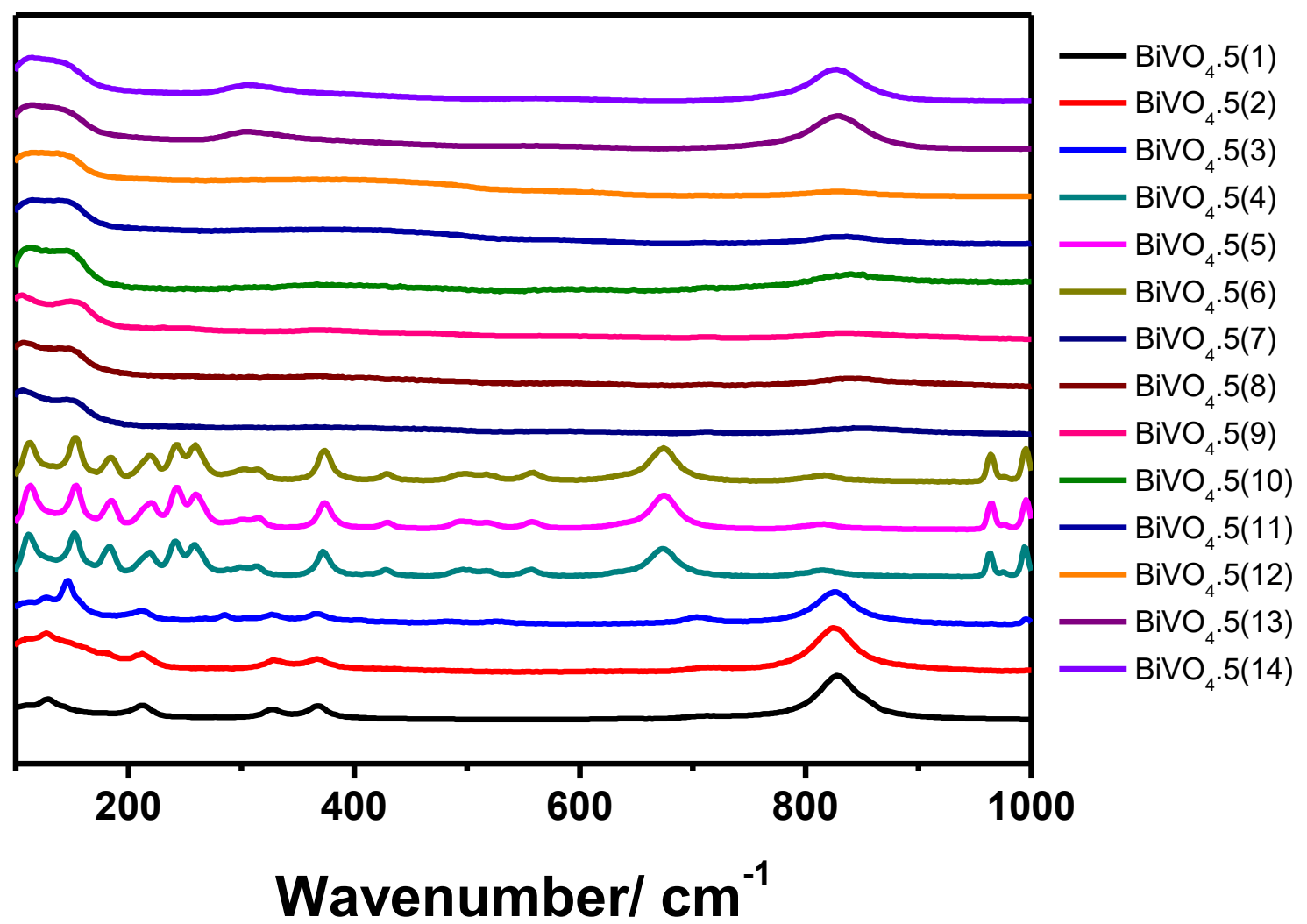

Figure S23. Raman spectra of $\mathrm{BiVO}_{4}-5(1-14)$. 


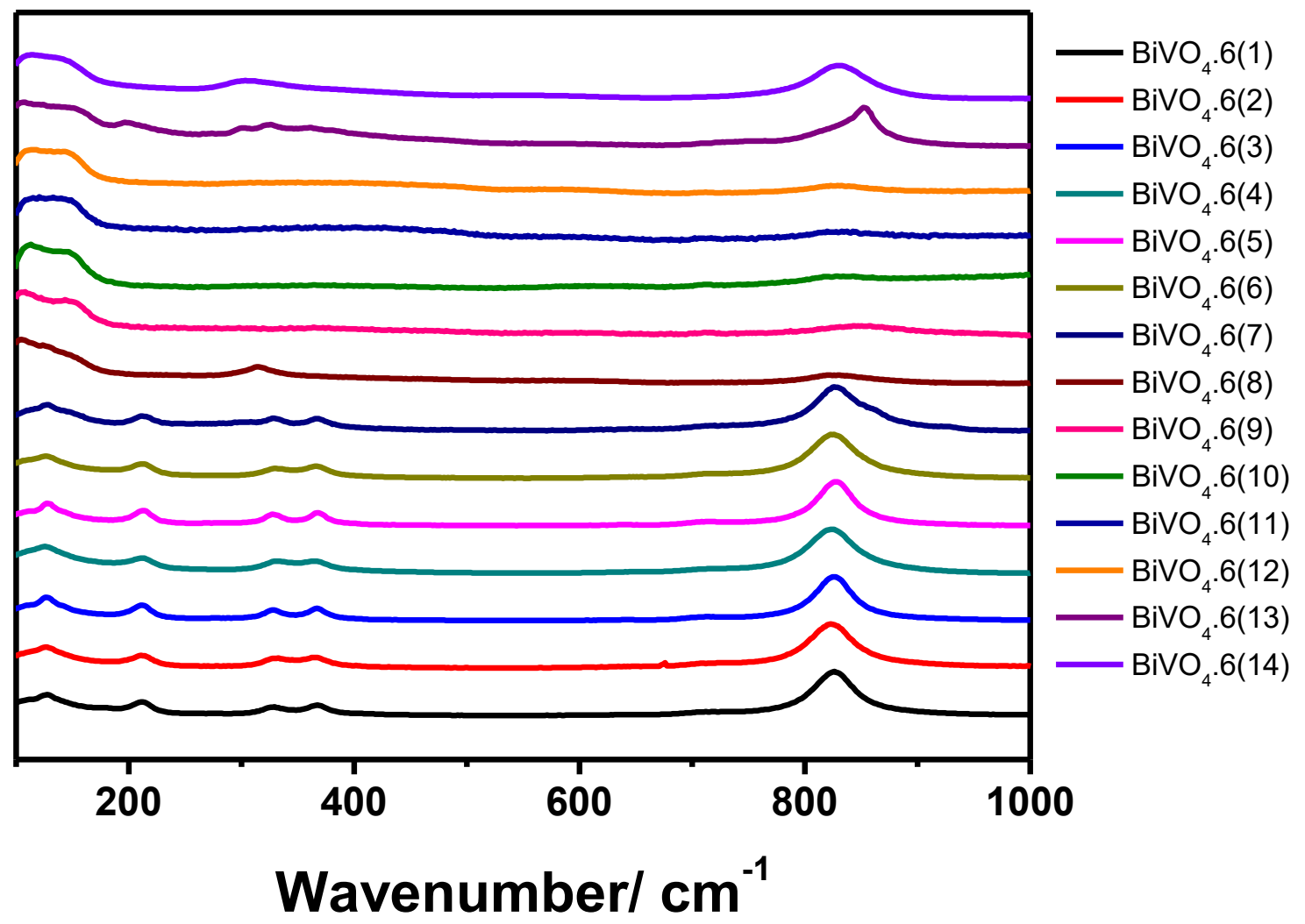

Figure S24. Raman spectra of $\mathrm{BiVO}_{4}-6(1-14)$. 


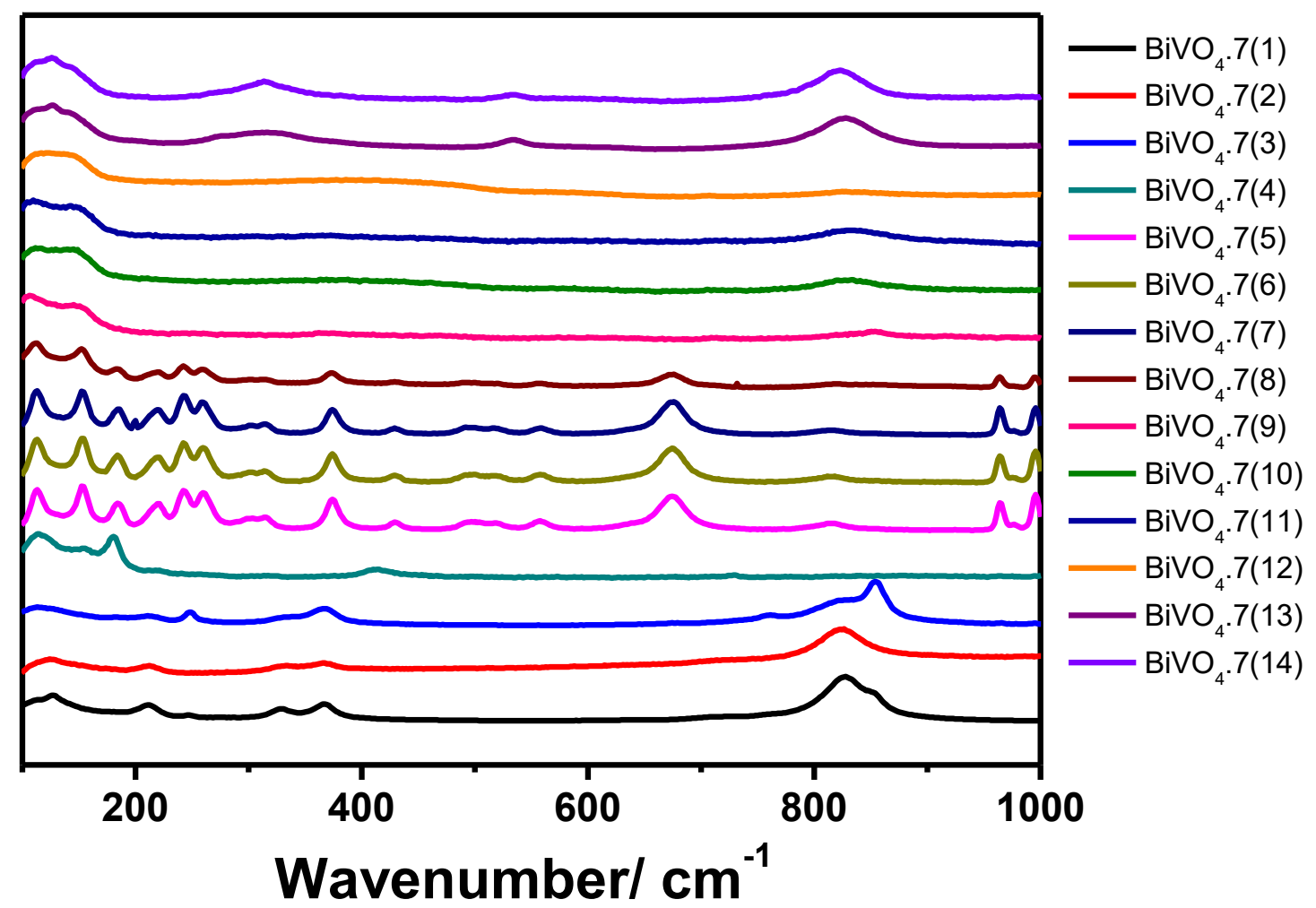

Figure S25. Raman spectra of $\mathrm{BiVO}_{4}-7(1-14)$. 


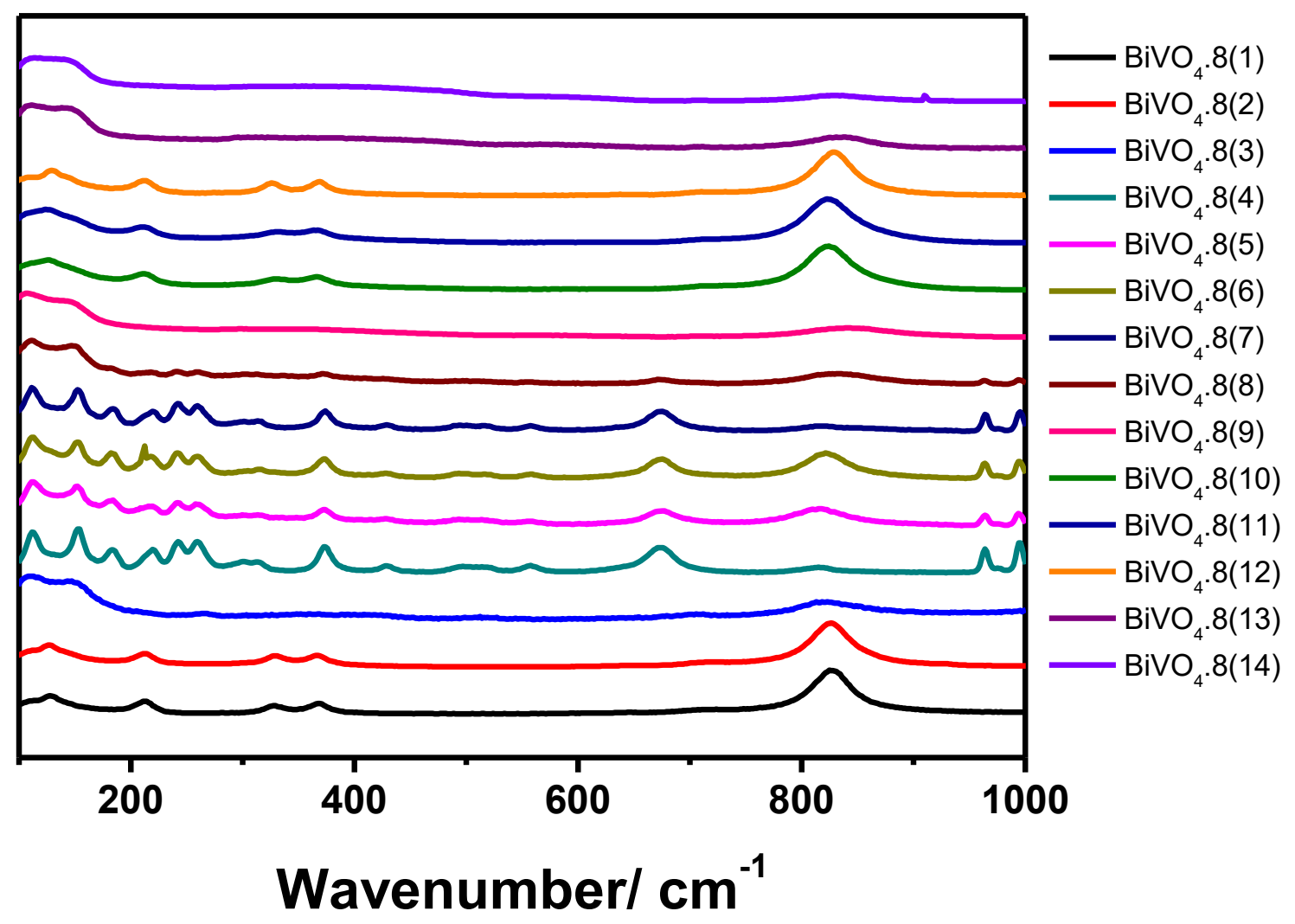

Figure S26. Raman spectra of $\mathrm{BiVO}_{4}-8(1-14)$. 


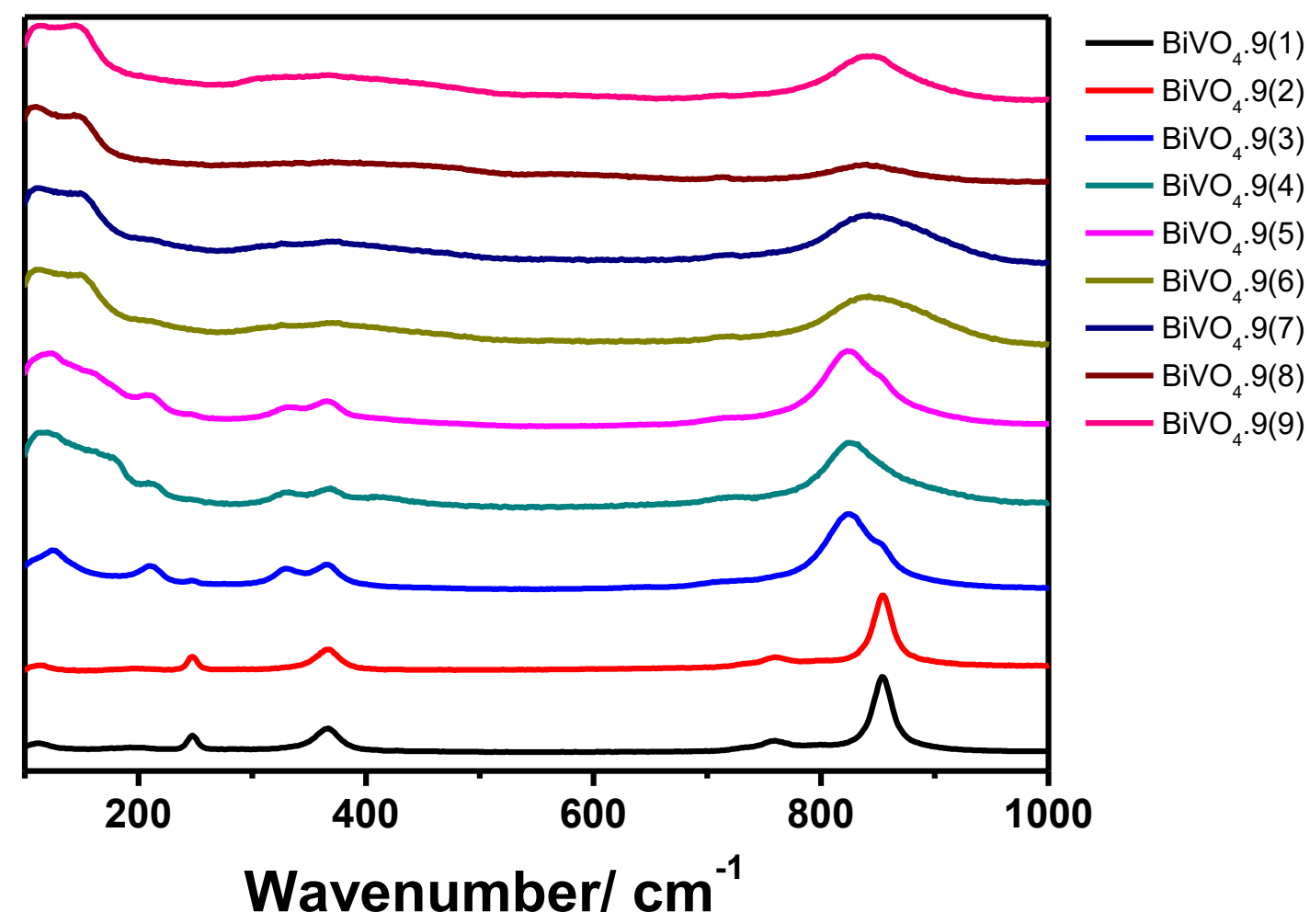

Figure S27. Raman spectra of $\mathrm{BiVO}_{4}-9(1-9)$. 


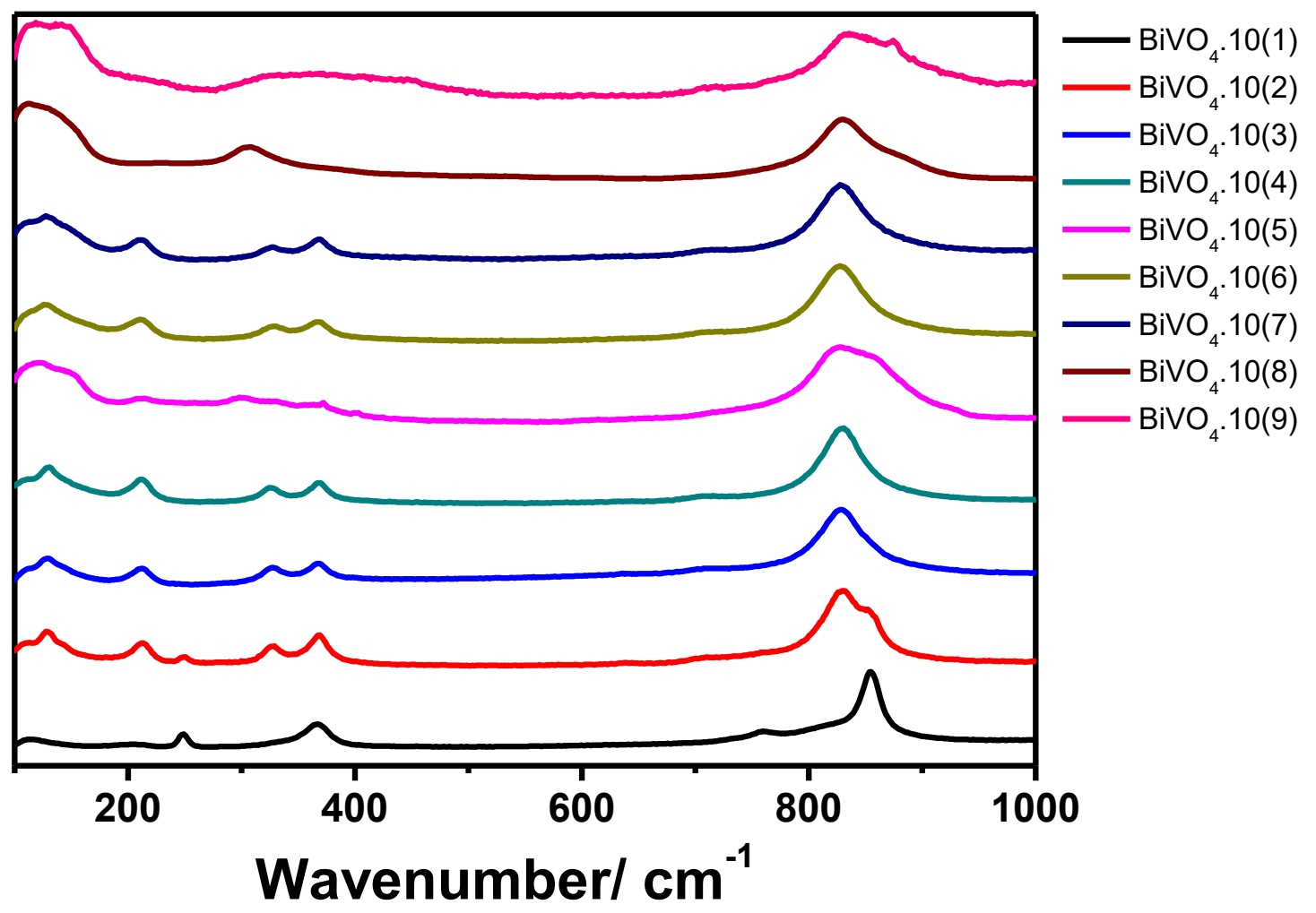

Figure S28. Raman spectra of $\mathrm{BiVO}_{4}-10(1-9)$. 


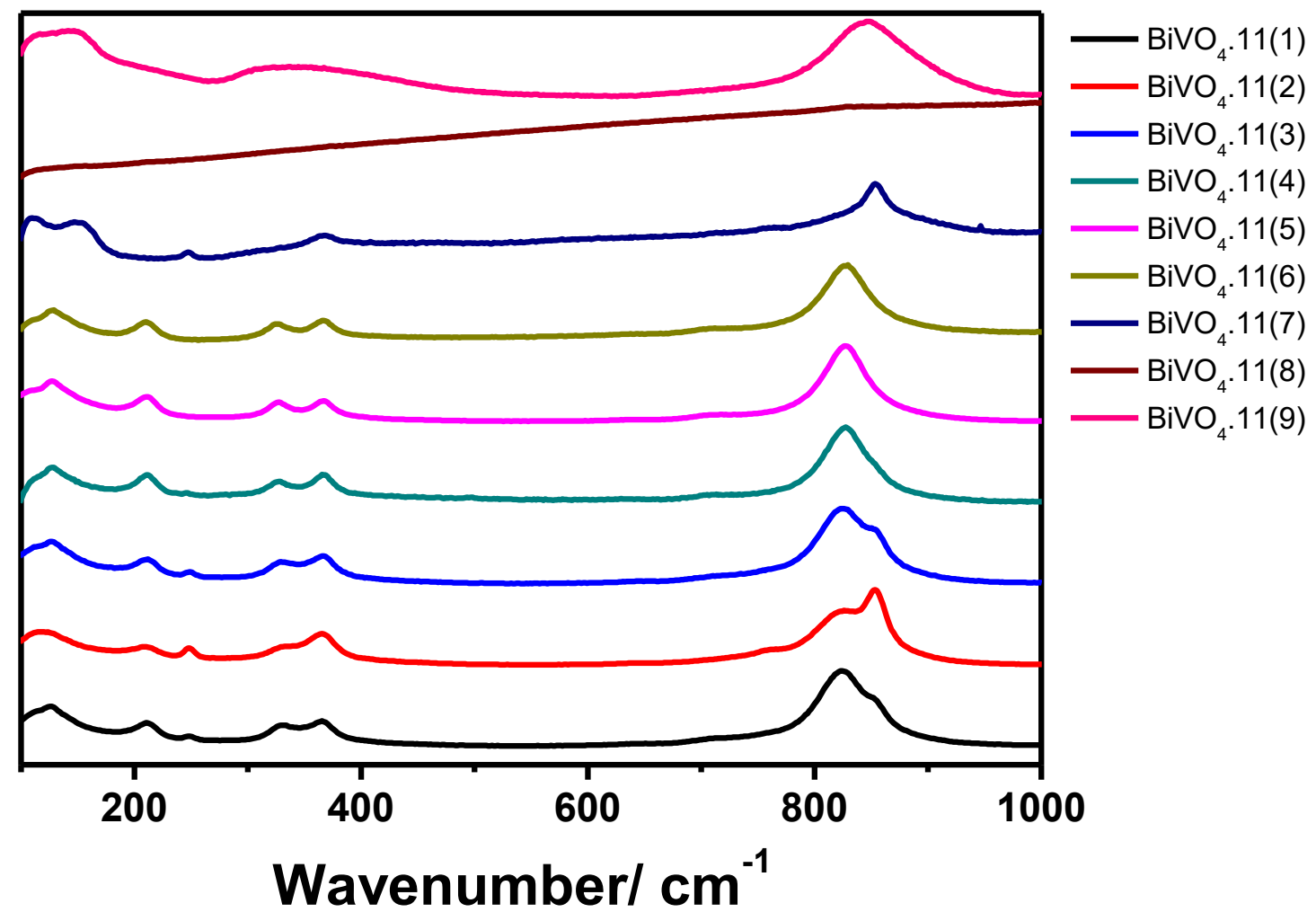

Figure S29. Raman spectra of $\mathrm{BiVO}_{4}-11(1-9)$. 


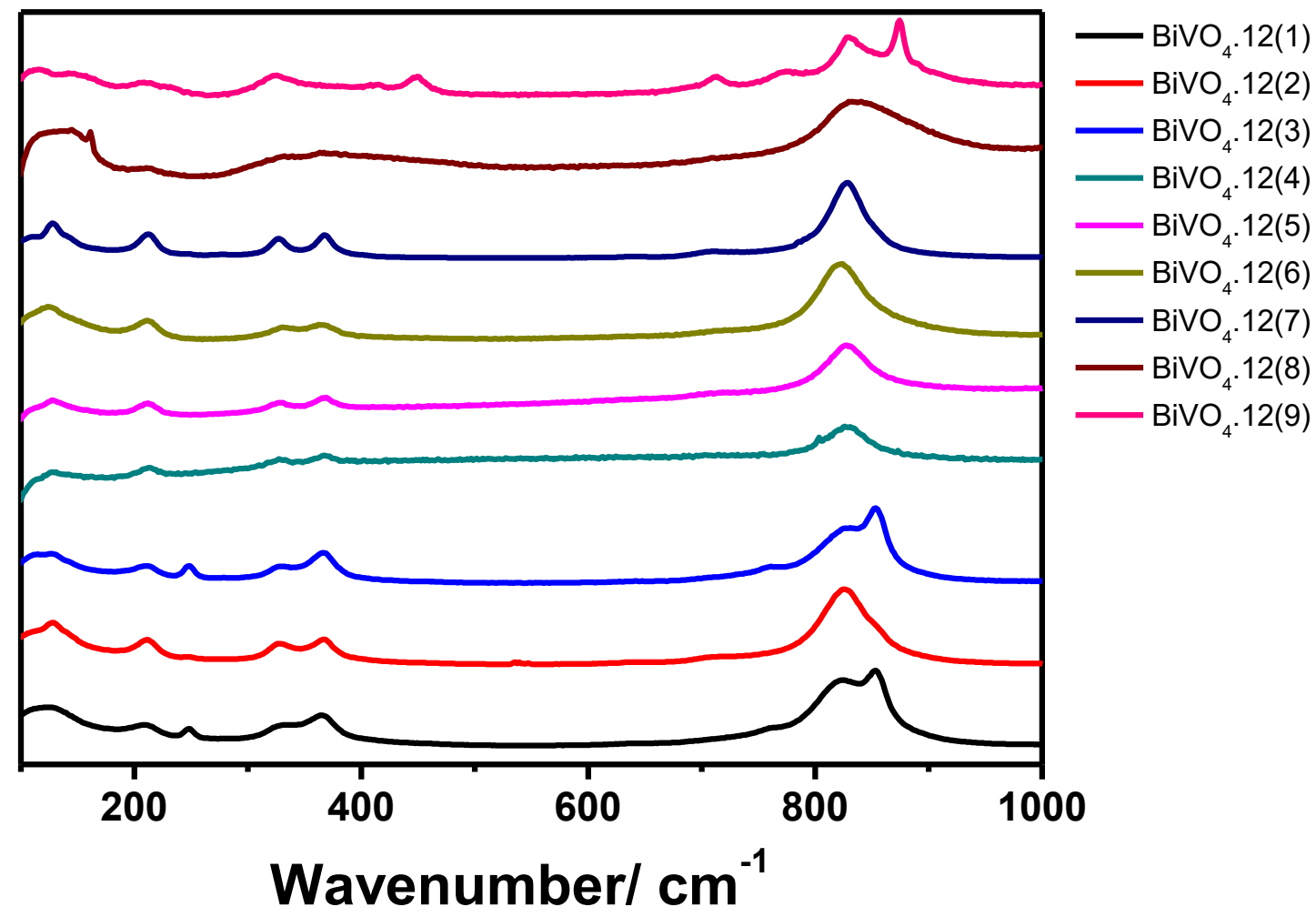

Figure S30. Raman spectra of $\mathrm{BiVO}_{4}-12(1-9)$. 


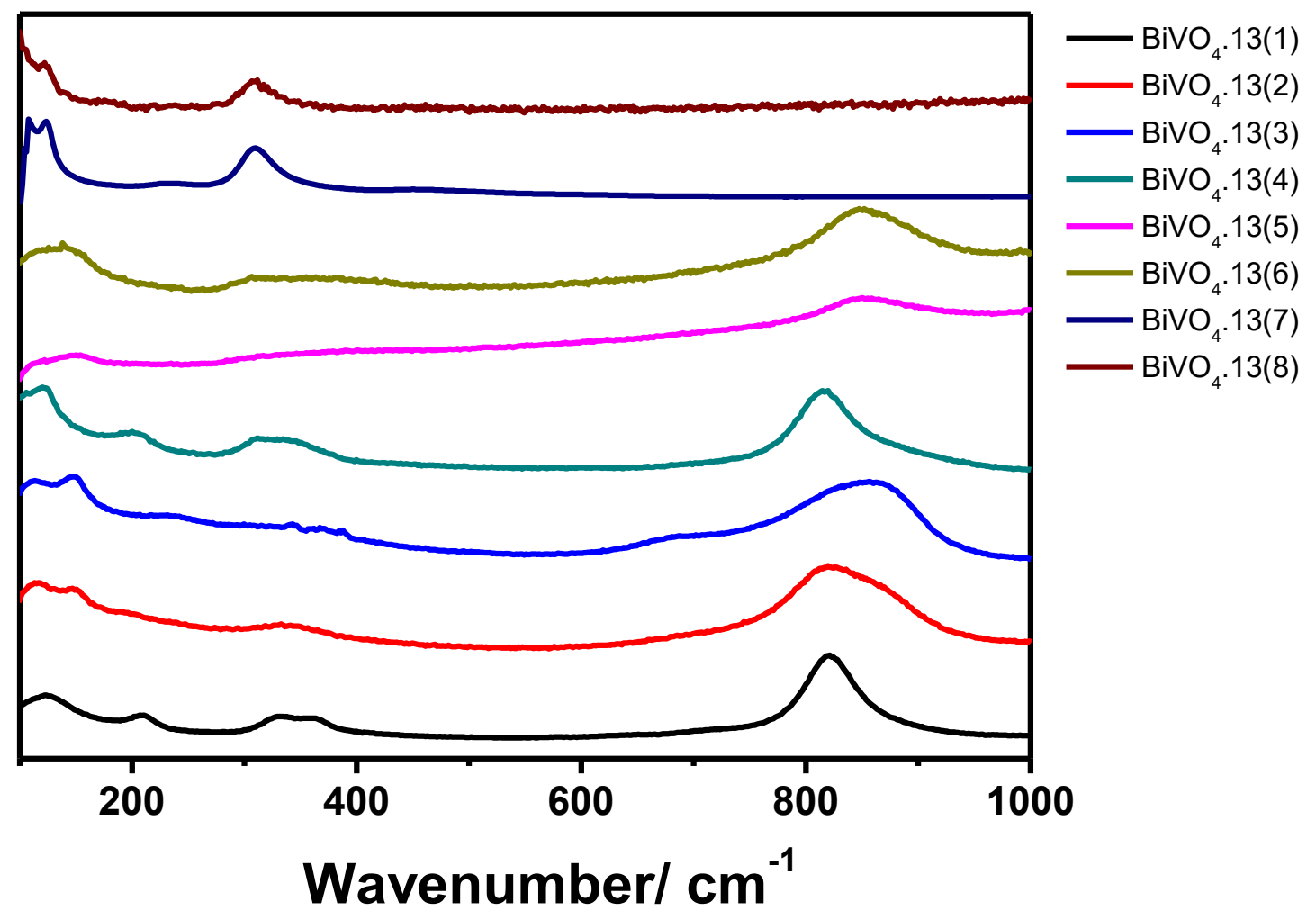

Figure S31. Raman spectra of $\mathrm{BiVO}_{4}-13(1-8)$. 


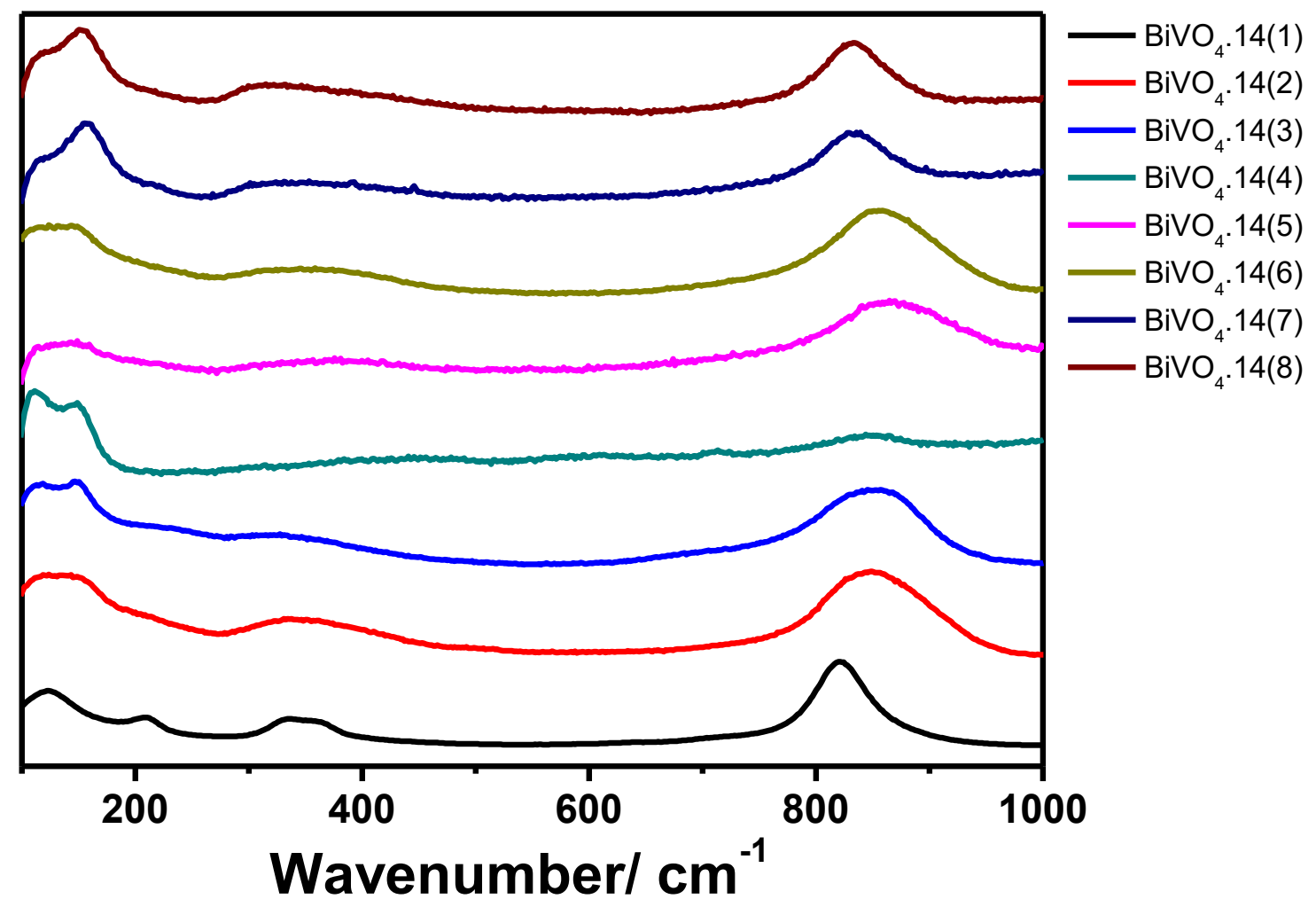

Figure S32. Raman spectra of $\mathrm{BiVO}_{4}-14(1-8)$. 


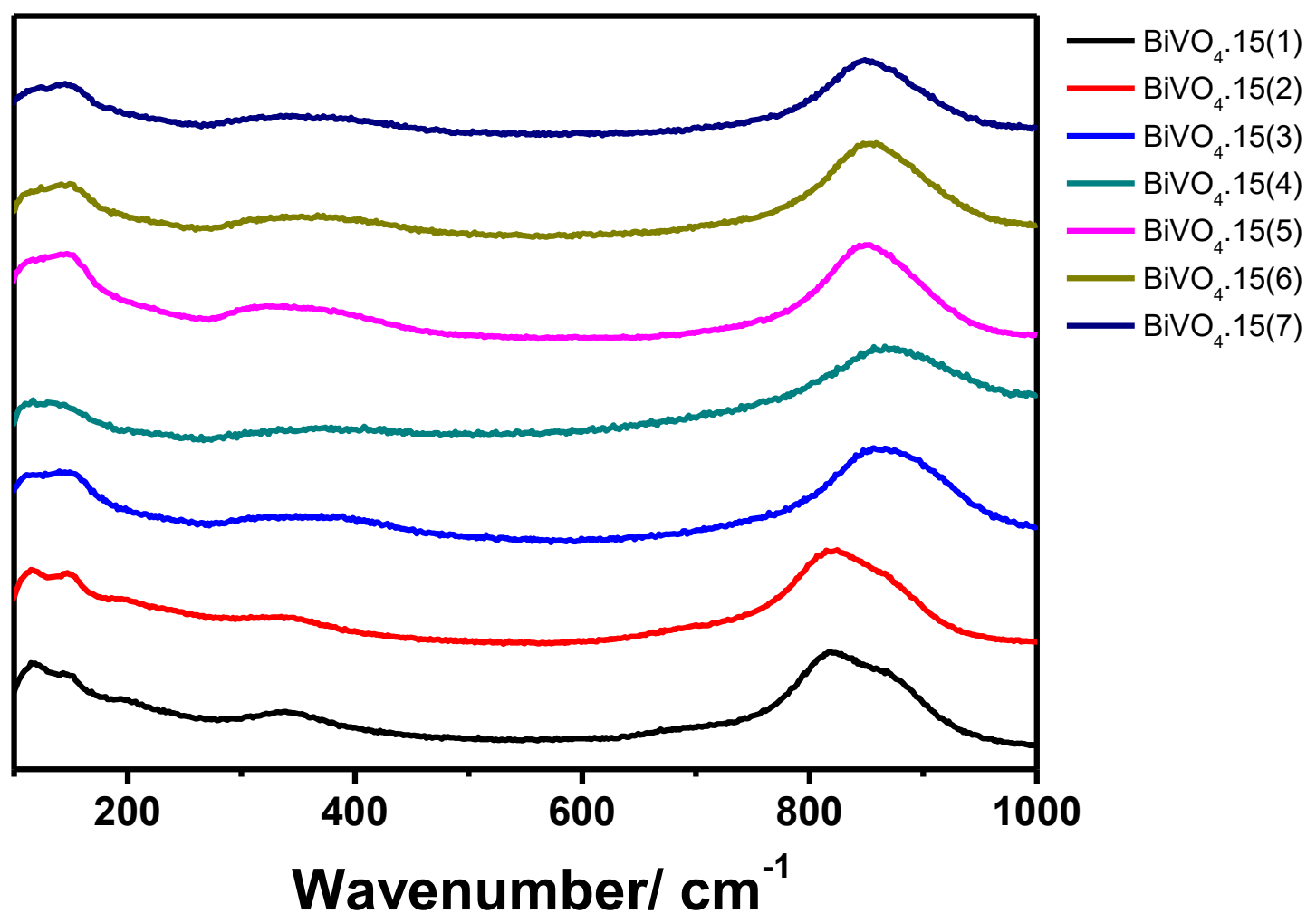

Figure S33. Raman spectra of $\mathrm{BiVO}_{4}-15(1-7)$. 


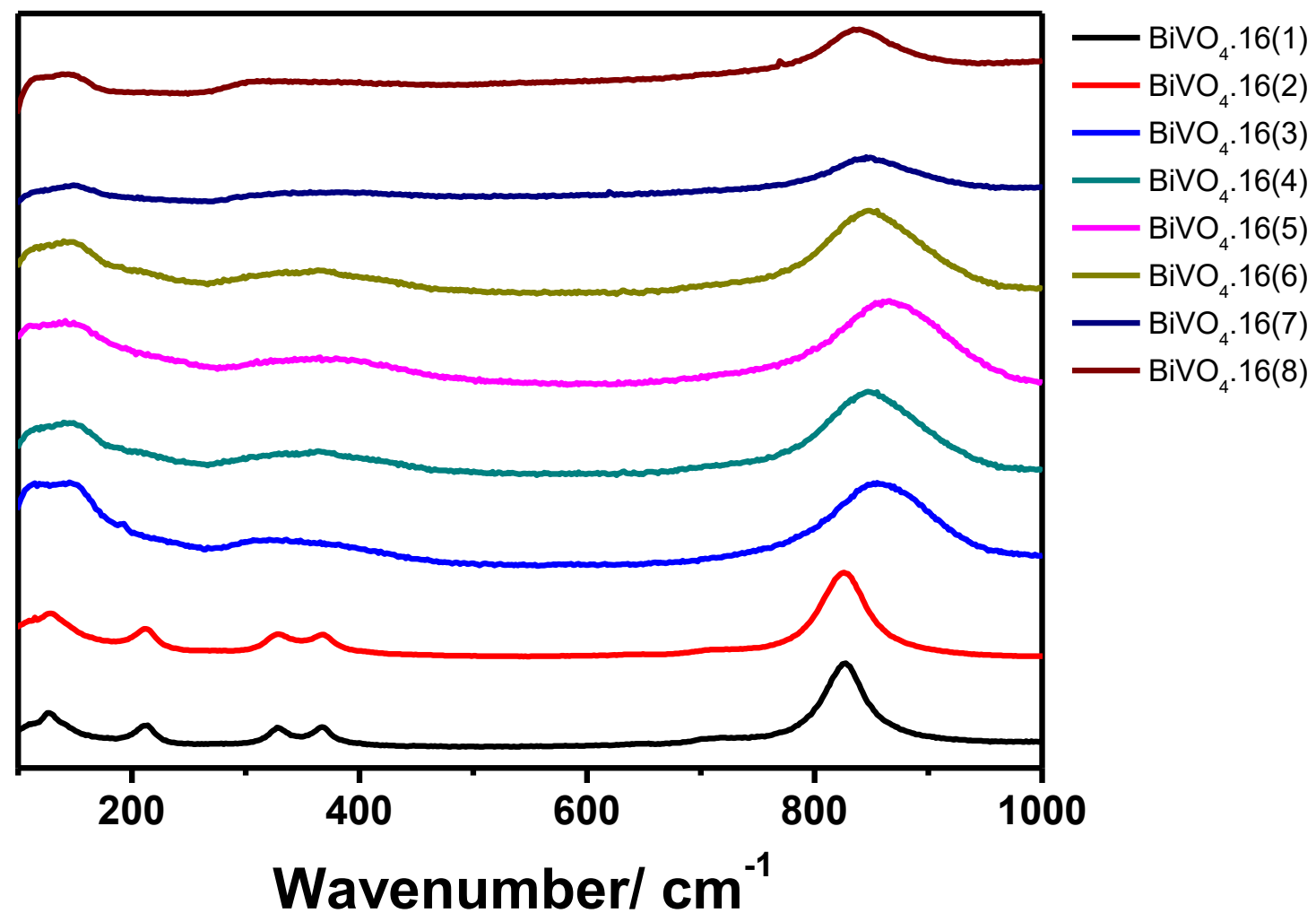

Figure S34. Raman spectra of $\mathrm{BiVO}_{4}-16(1-8)$. 


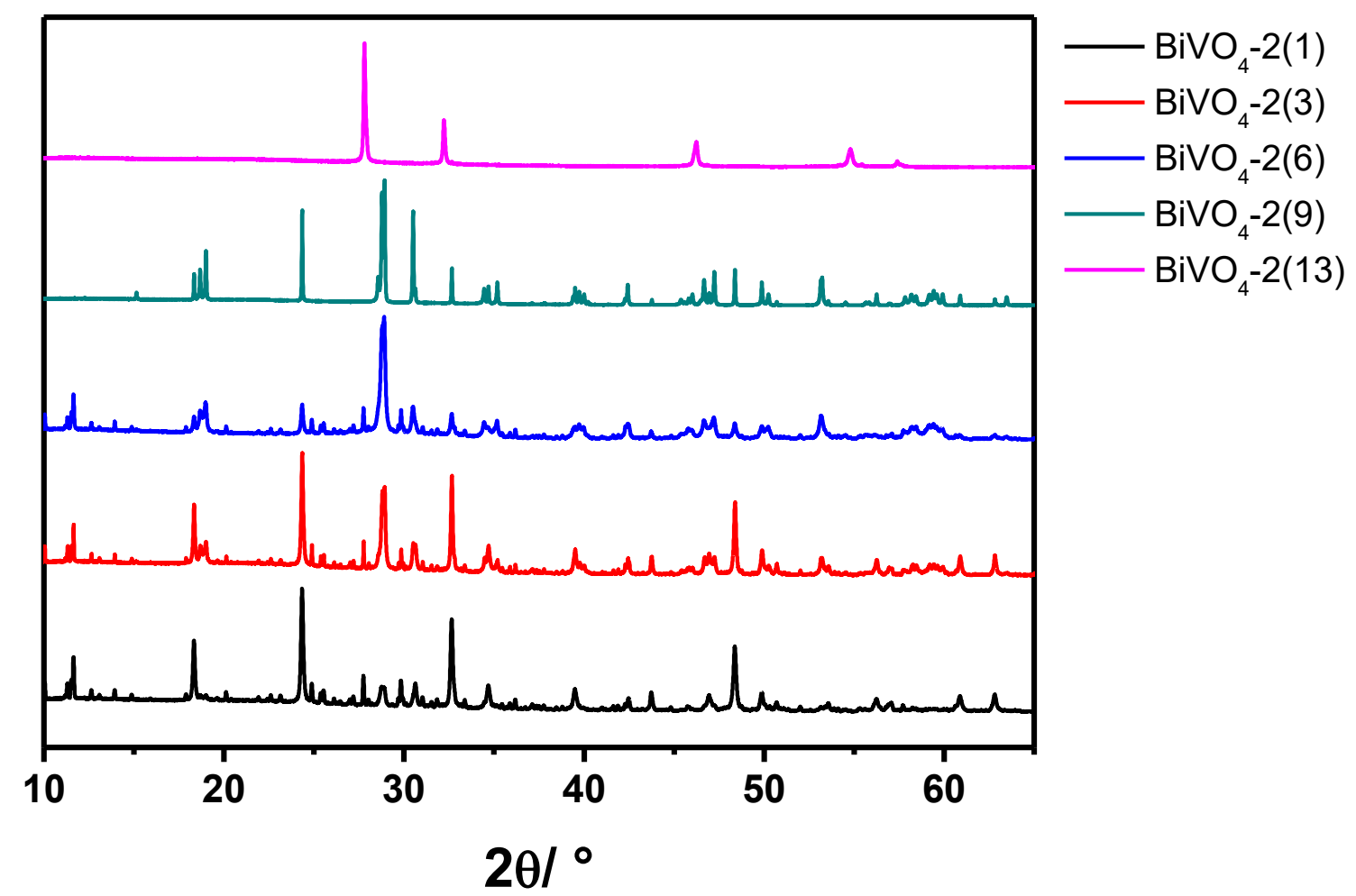

Figure S35. XRD diffractograms of $\mathrm{BiVO}_{4}-2(1), \mathrm{BiVO}_{4}-2(3), \mathrm{BiVO}_{4}-2(6), \mathrm{BiVO}_{4}-2(9)$ and $\mathrm{BiVO}_{4}-2(13)$. 


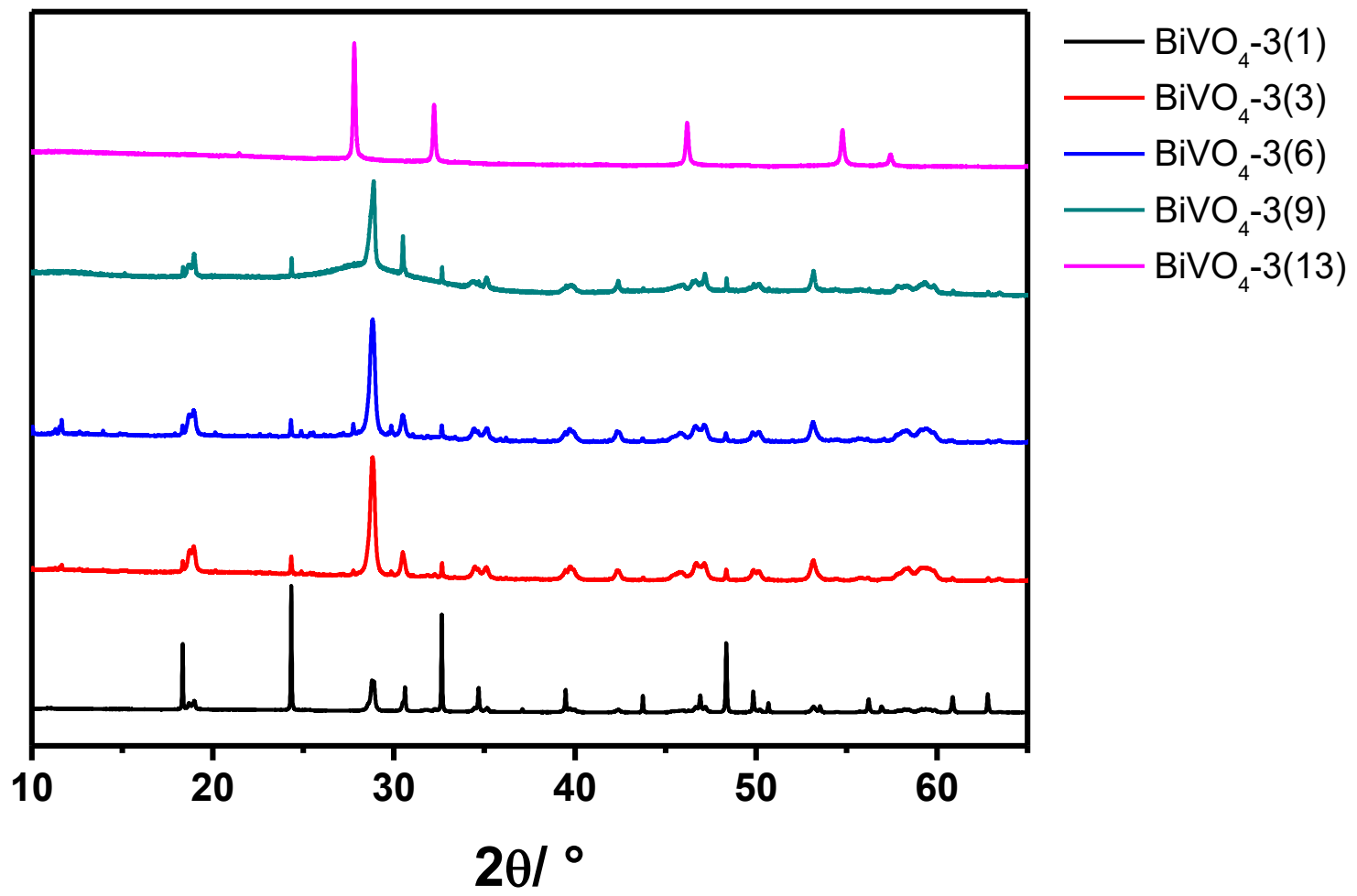

Figure S36. XRD diffractograms of $\mathrm{BiVO}_{4}-3(1), \mathrm{BiVO}_{4}-3(3), \mathrm{BiVO}_{4}-3(6), \mathrm{BiVO}_{4}-3(9)$ and $\mathrm{BiVO}_{4}-3(13)$. 


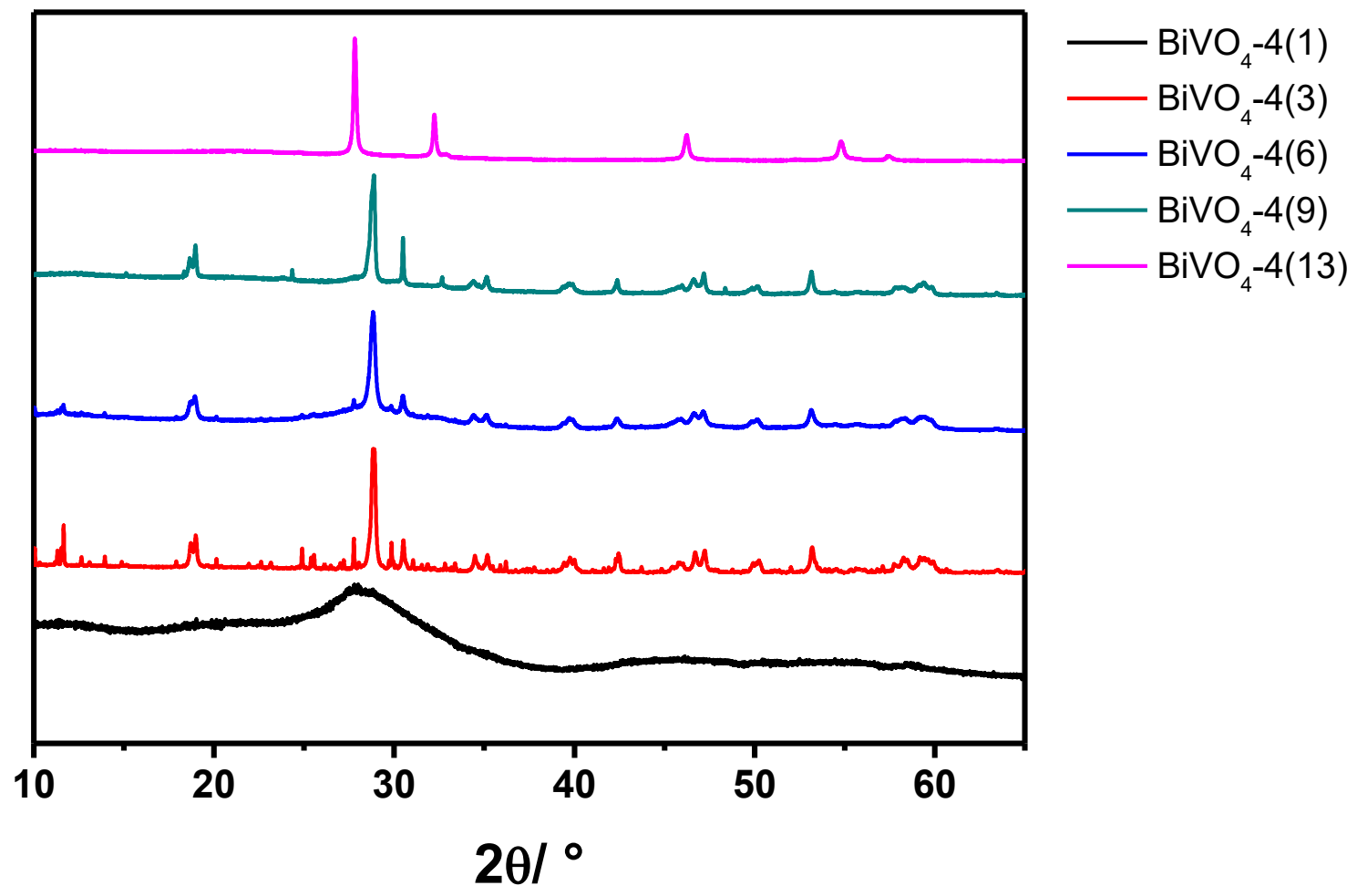

Figure S37. XRD diffractograms of $\mathrm{BiVO}_{4}-4(1), \mathrm{BiVO}_{4}-4(3), \mathrm{BiVO}_{4}-4(6), \mathrm{BiVO}_{4}-4(9)$ and $\mathrm{BiVO}_{4}-4(13)$. 


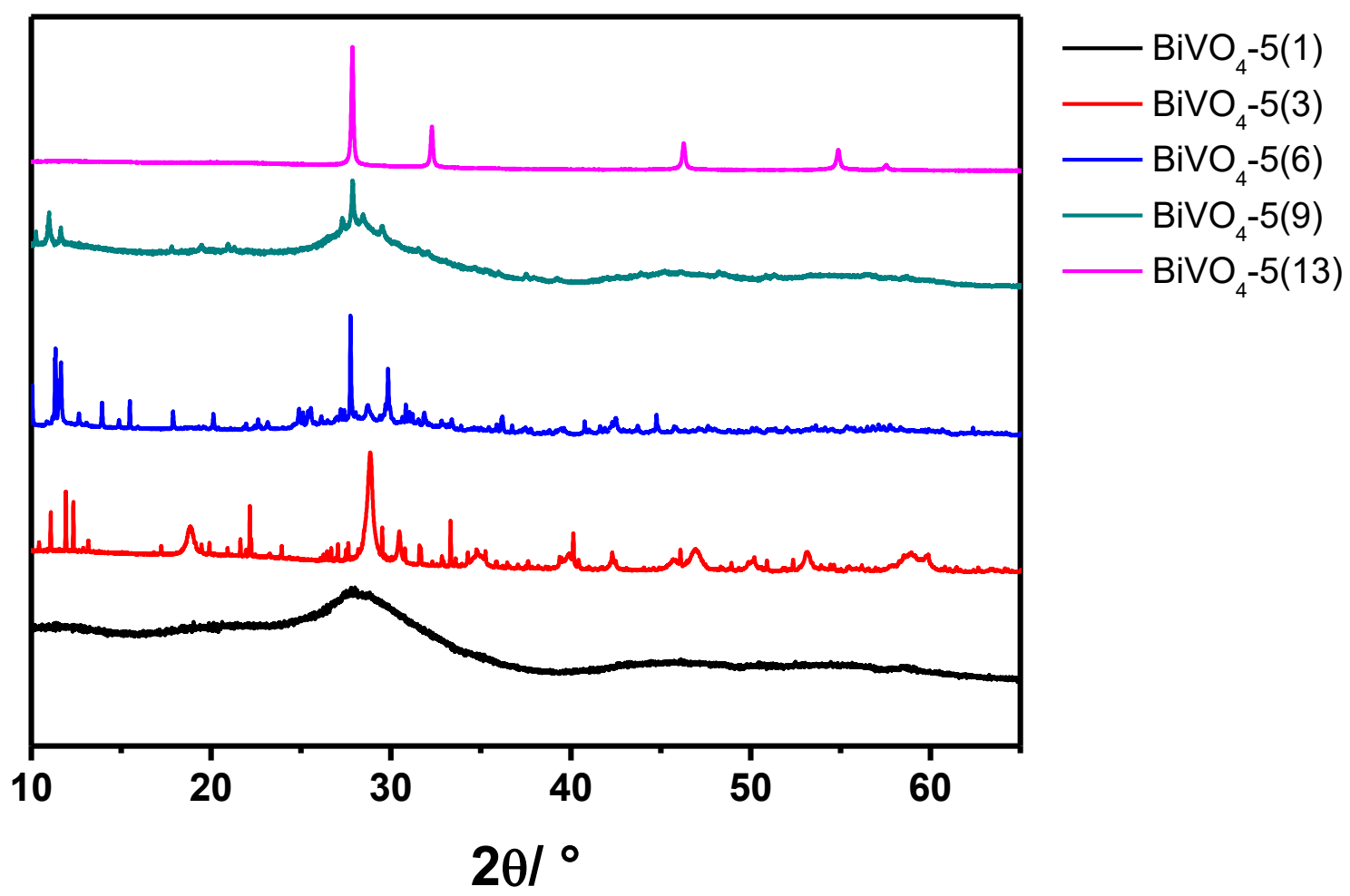

Figure S38. XRD diffractograms of $\mathrm{BiVO}_{4}-5(1), \mathrm{BiVO}_{4}-5(3), \mathrm{BiVO}_{4}-5(6), \mathrm{BiVO}_{4}-5(9)$ and $\mathrm{BiVO}_{4}-5(13)$. 


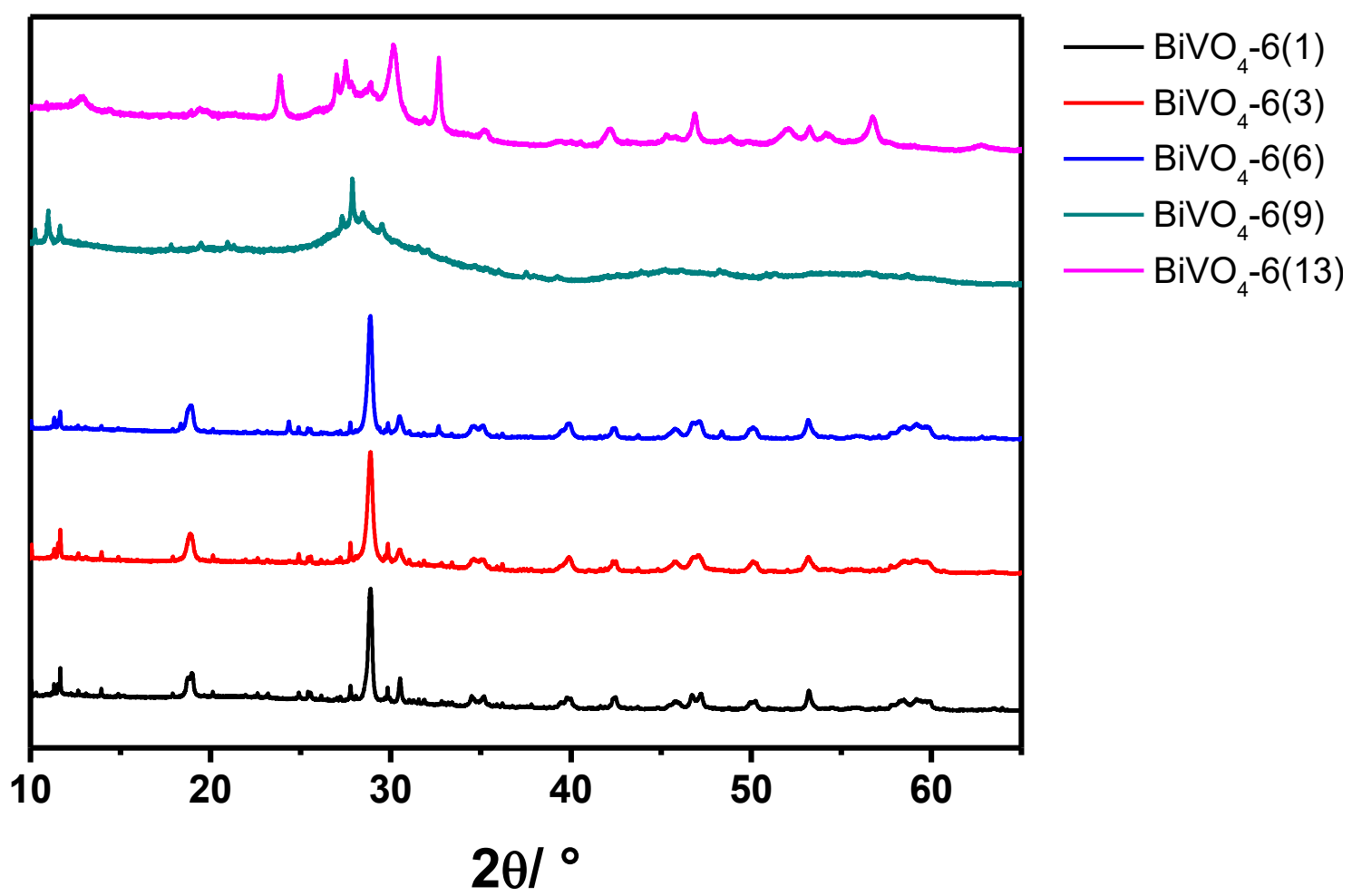

Figure S39. XRD diffractograms of $\mathrm{BiVO}_{4}-6(1), \mathrm{BiVO}_{4}-6(3), \mathrm{BiVO}_{4}-6(6), \mathrm{BiVO}_{4}-6(9)$ and $\mathrm{BiVO}_{4}-6(13)$. 


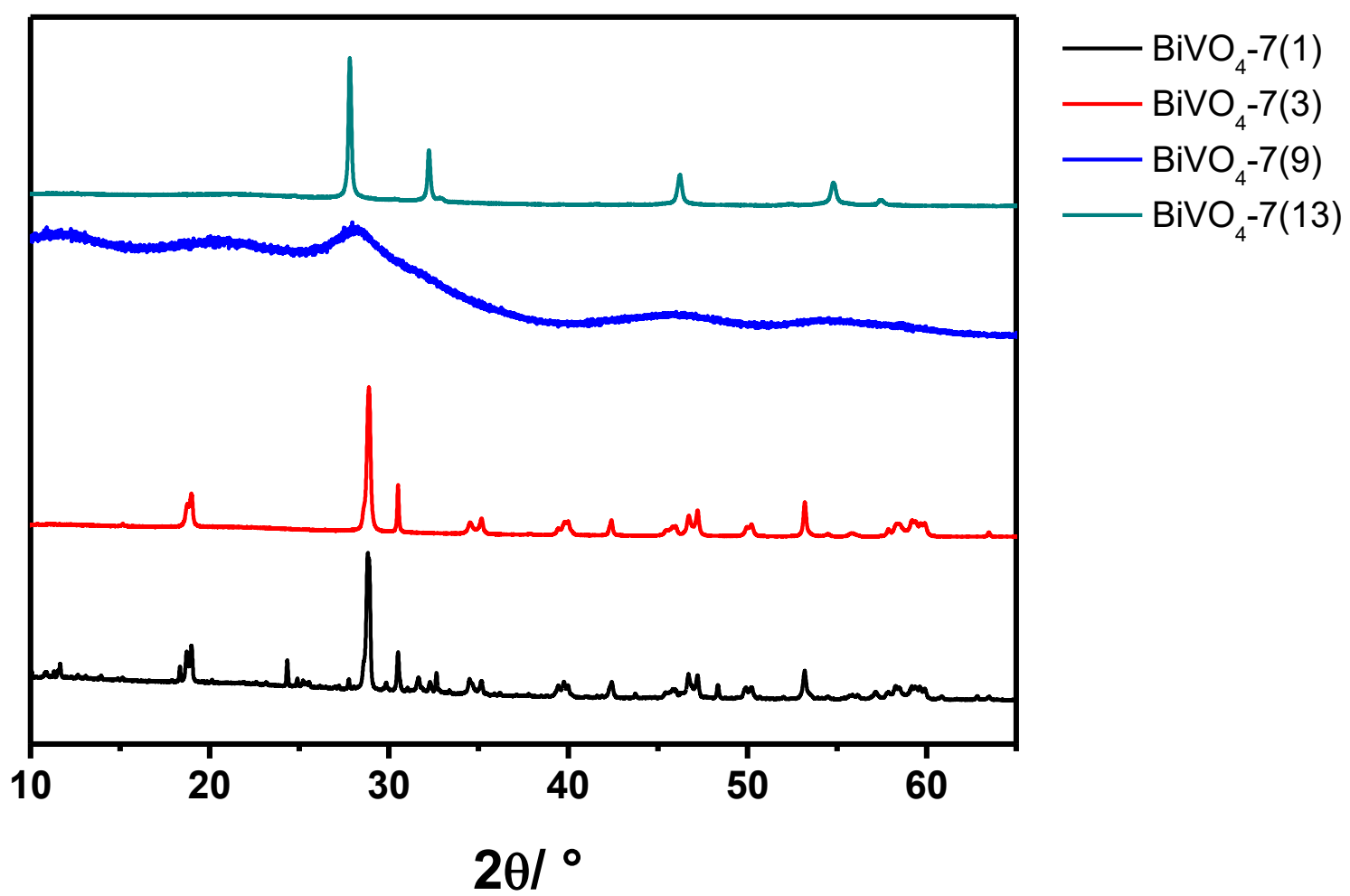

Figure S40. XRD diffractograms of $\mathrm{BiVO}_{4}-7(1), \mathrm{BiVO}_{4}-7(3), \mathrm{BiVO}_{4}-7(9)$ and $\mathrm{BiVO}_{4}-7(13)$. 


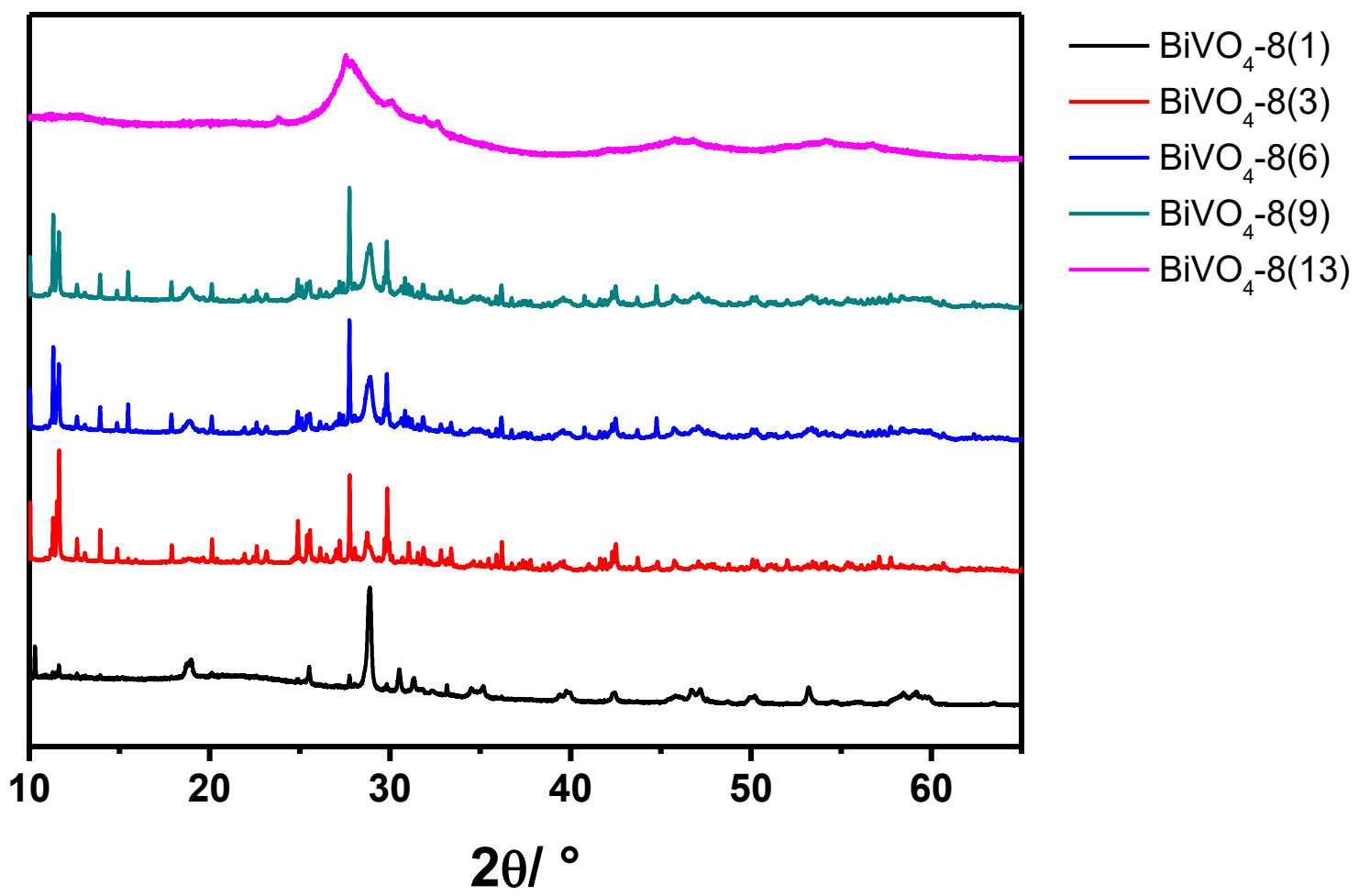

Figure S41. XRD diffractograms of $\mathrm{BiVO}_{4}-8(1), \mathrm{BiVO}_{4}-8(3), \mathrm{BiVO}_{4}-6(6), \mathrm{BiVO}_{4}-8(9)$ and $\mathrm{BiVO}_{4}-8(13)$. 


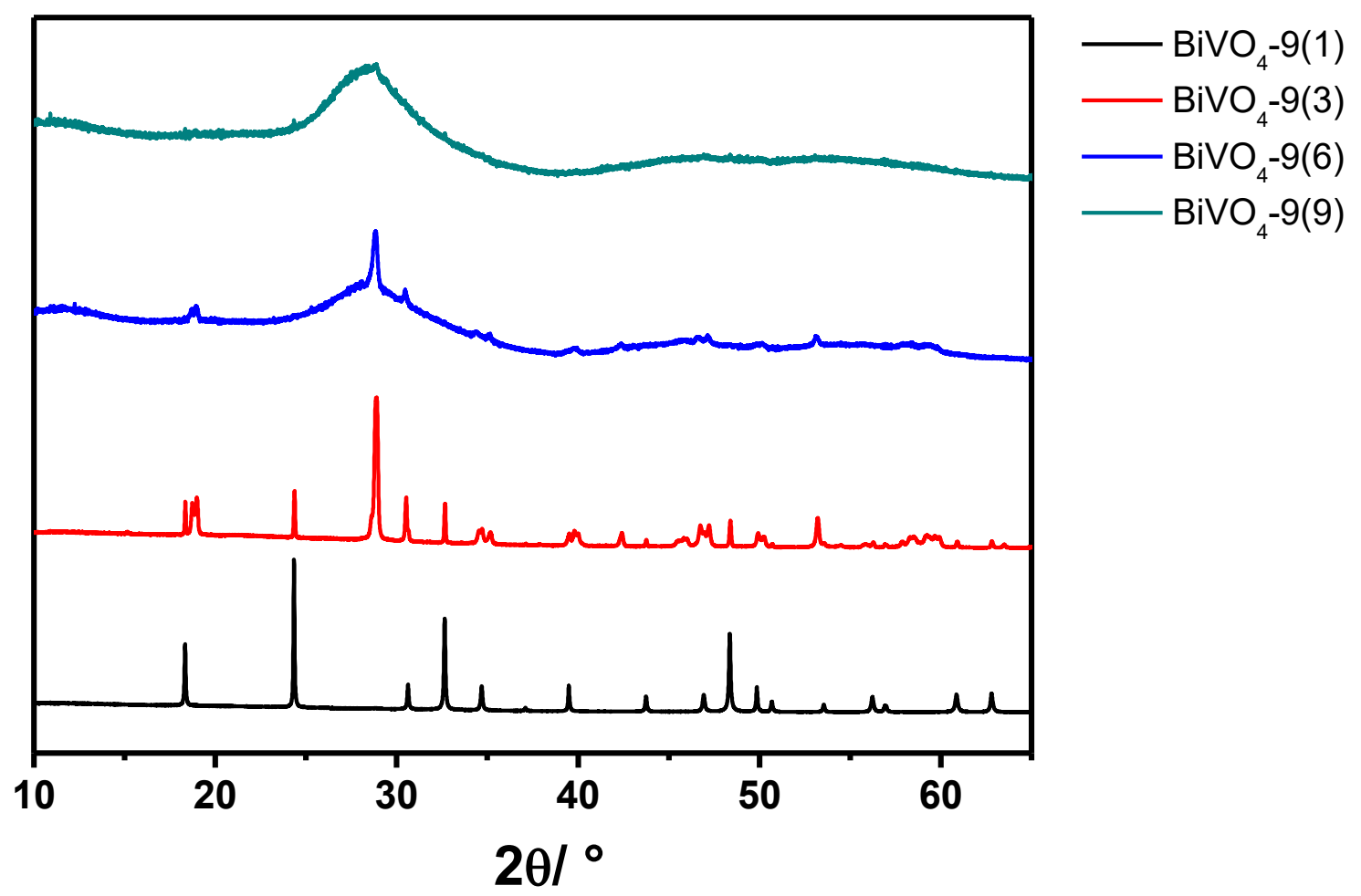

Figure S42. XRD diffractograms of $\mathrm{BiVO}_{4}-9(1), \mathrm{BiVO}_{4}-9(3), \mathrm{BiVO}_{4}-9(6)$ and $\mathrm{BiVO}_{4}-9(9)$. 


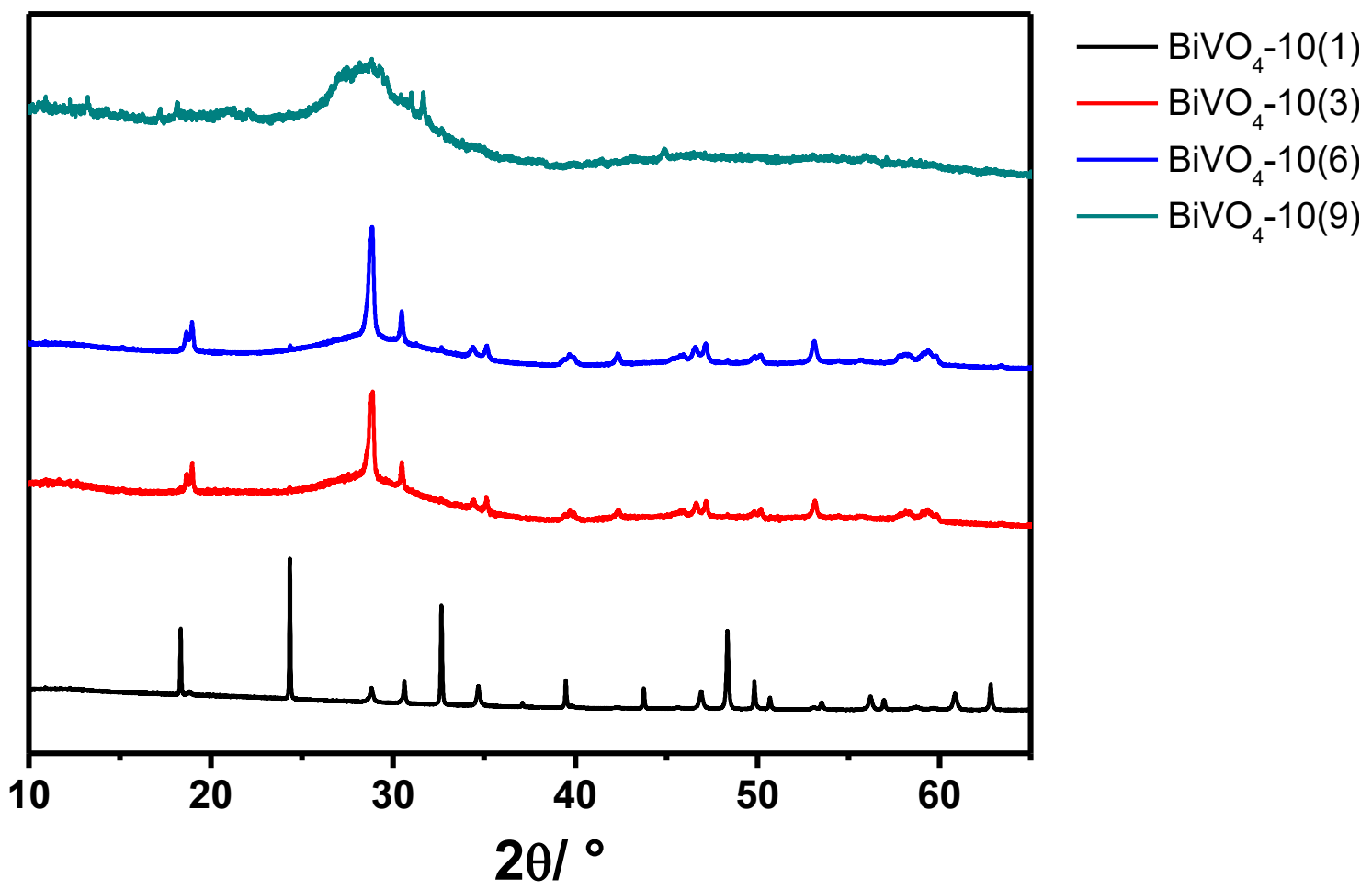

Figure S43. XRD diffractograms of $\mathrm{BiVO}_{4}-10(1), \mathrm{BiVO}_{4}-10(3), \mathrm{BiVO}_{4}-10(6)$ and $\mathrm{BiVO}_{4-}$ 10(9). 


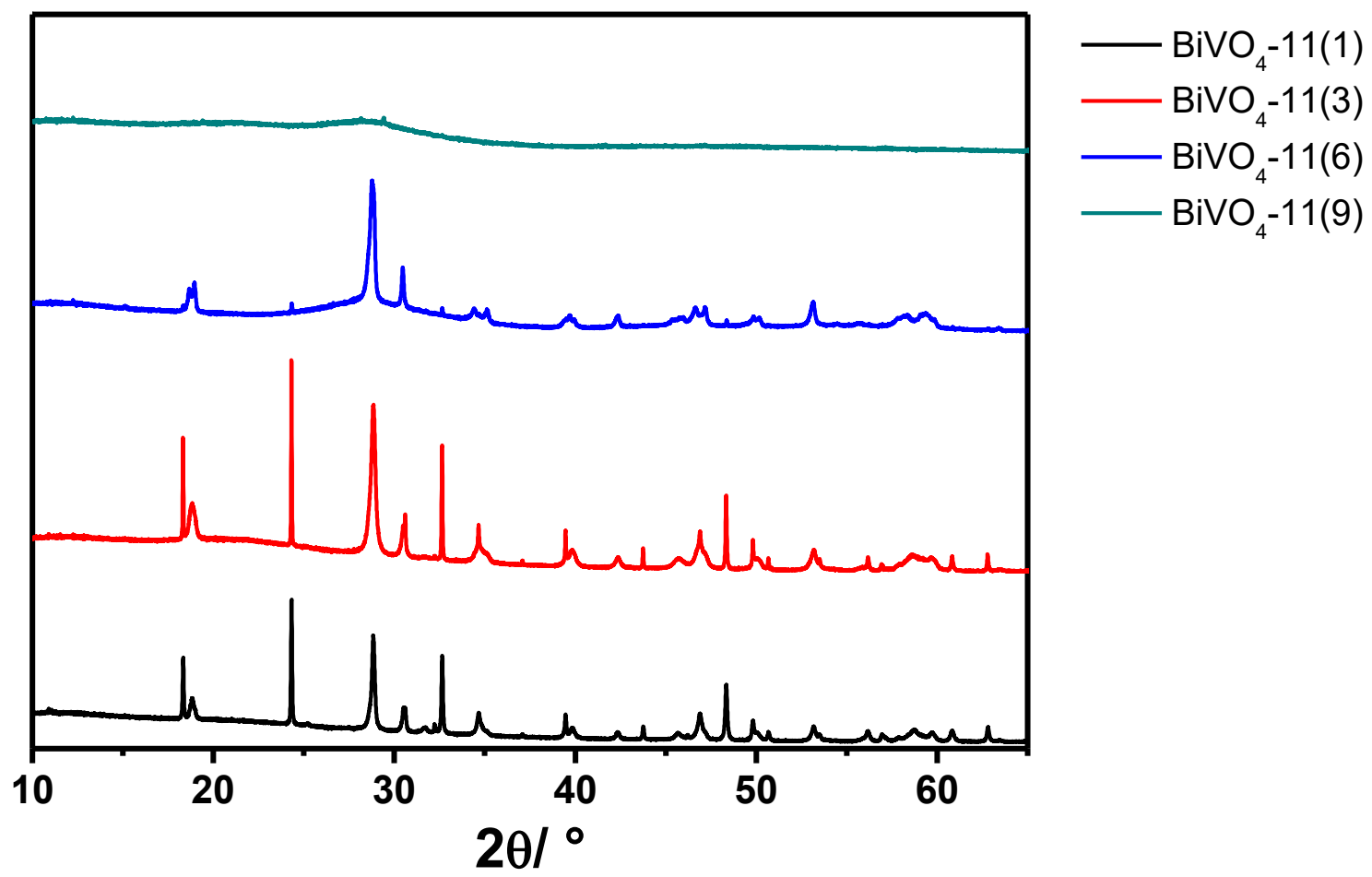

Figure S44. XRD diffractograms of $\mathrm{BiVO}_{4}-11(1), \mathrm{BiVO}_{4}-11(3), \mathrm{BiVO}_{4}-11(6)$ and $\mathrm{BiVO}_{4}-$ 11(9). 


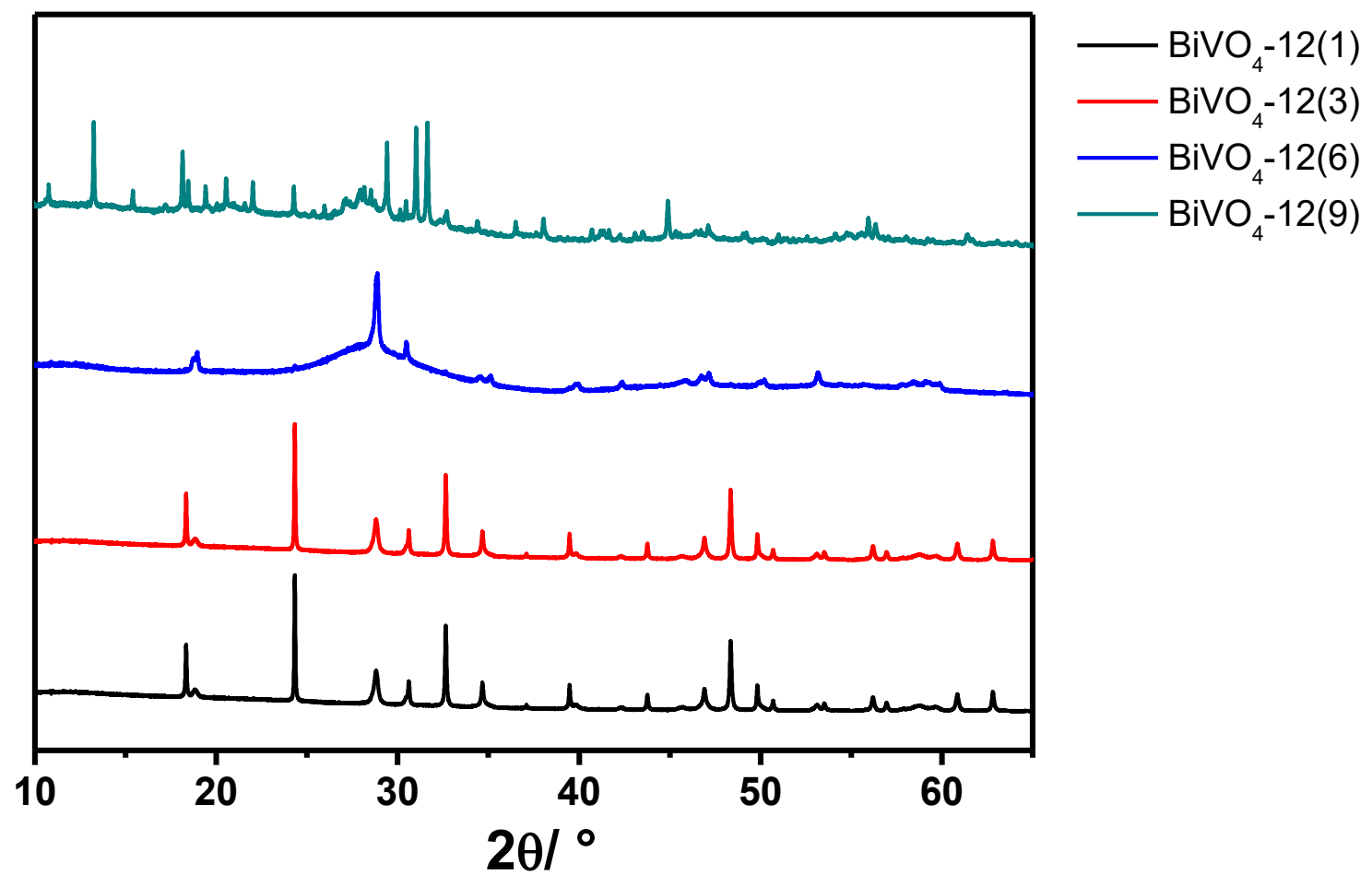

Figure S45. XRD diffractograms of $\mathrm{BiVO}_{4}-12(1), \mathrm{BiVO}_{4}-12(3), \mathrm{BiVO}_{4}-12(6)$ and $\mathrm{BiVO}_{4}-$ 12(9). 


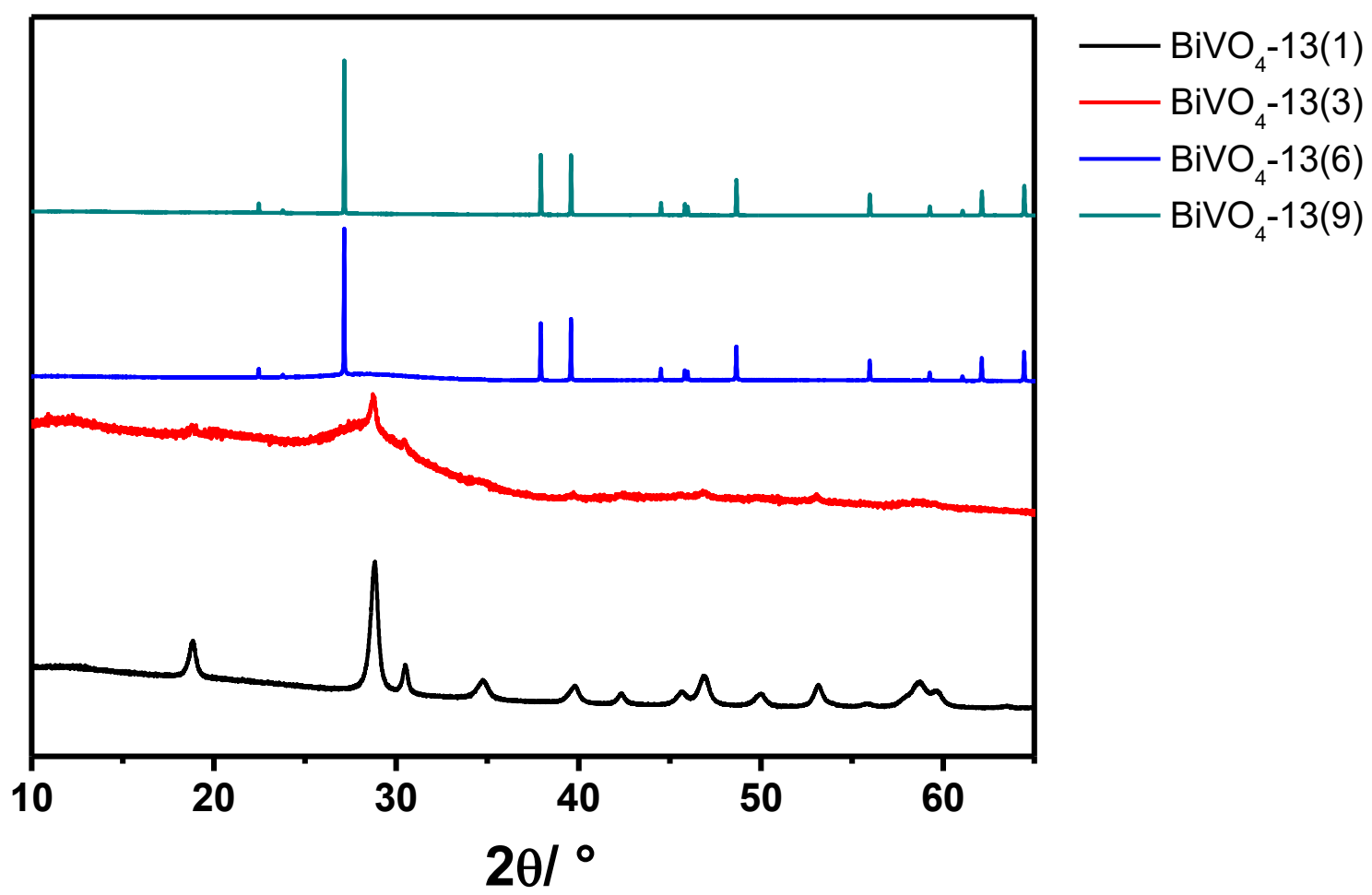

Figure S46. XRD diffractograms of $\mathrm{BiVO}_{4}-13(1), \mathrm{BiVO}_{4}-13(3), \mathrm{BiVO}_{4}-13(6)$ and $\mathrm{BiVO}_{4}-$ 13(9). 


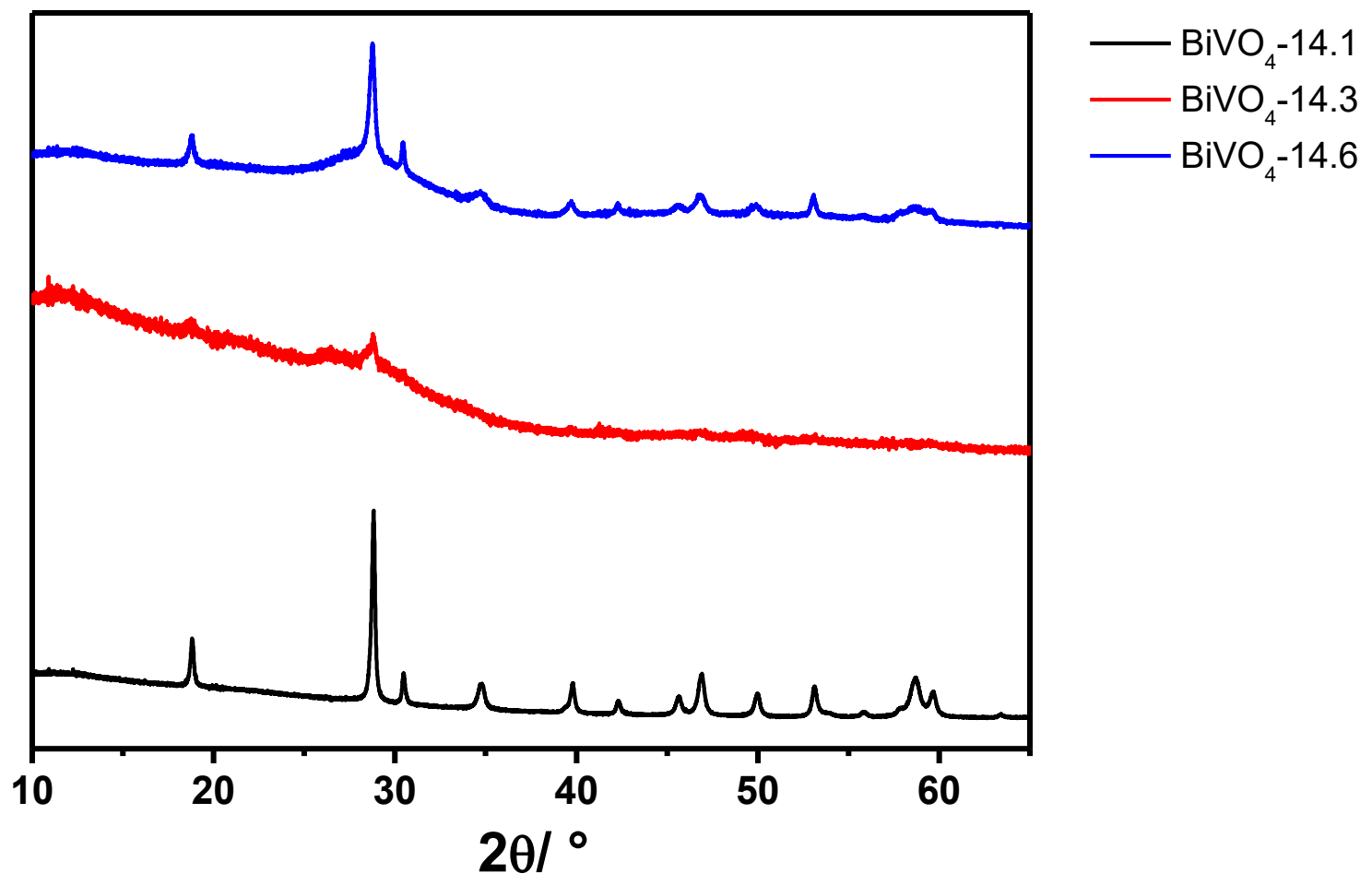

Figure S47. XRD diffractograms of $\mathrm{BiVO}_{4}-14(1), \mathrm{BiVO}_{4}-14(3)$ and $\mathrm{BiVO}_{4}-14(6)$. 


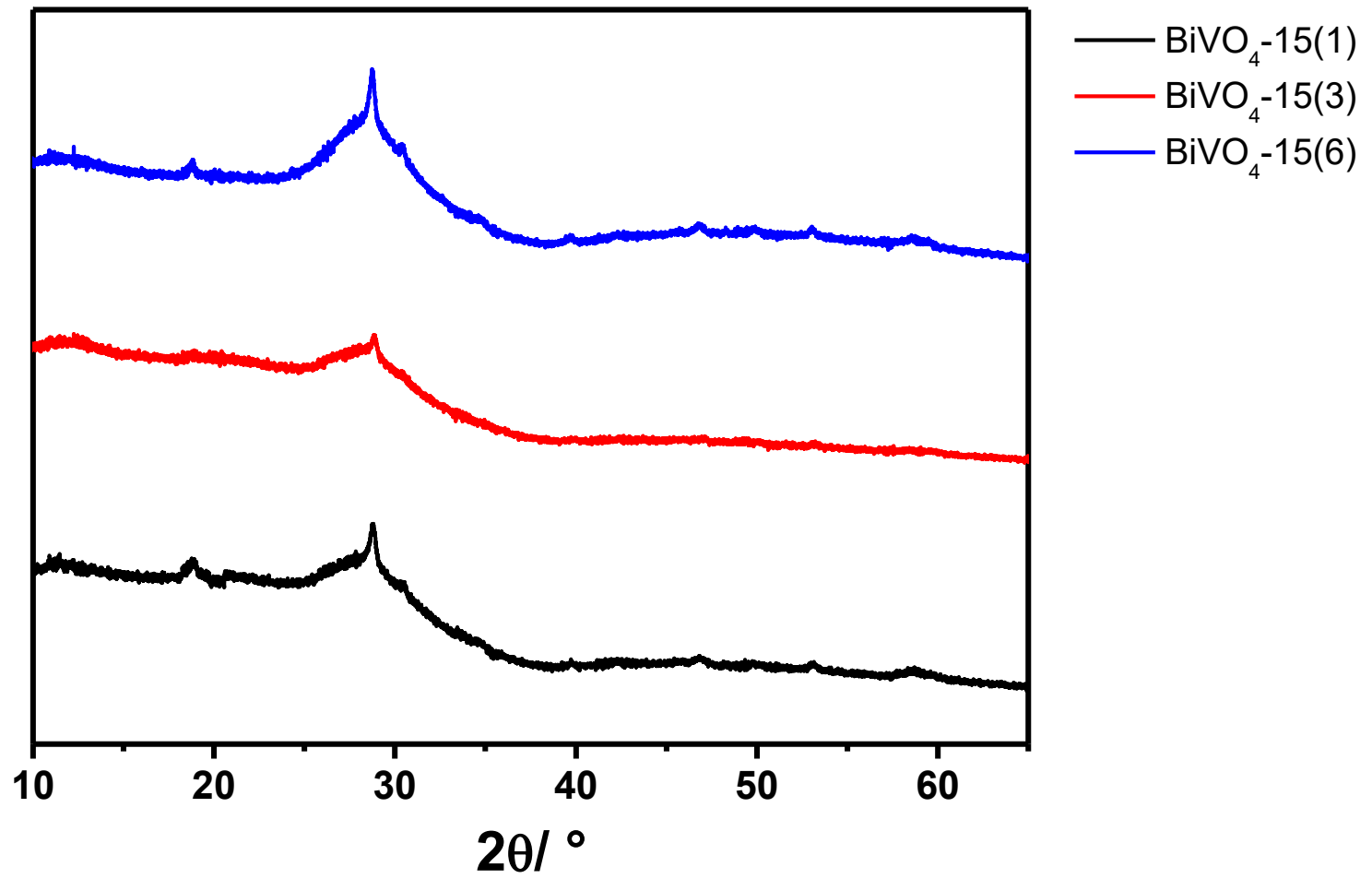

Figure S48. XRD diffractograms of $\mathrm{BiVO}_{4}-15(1), \mathrm{BiVO}_{4}-15(3)$ and $\mathrm{BiVO}_{4}-15(6)$. 


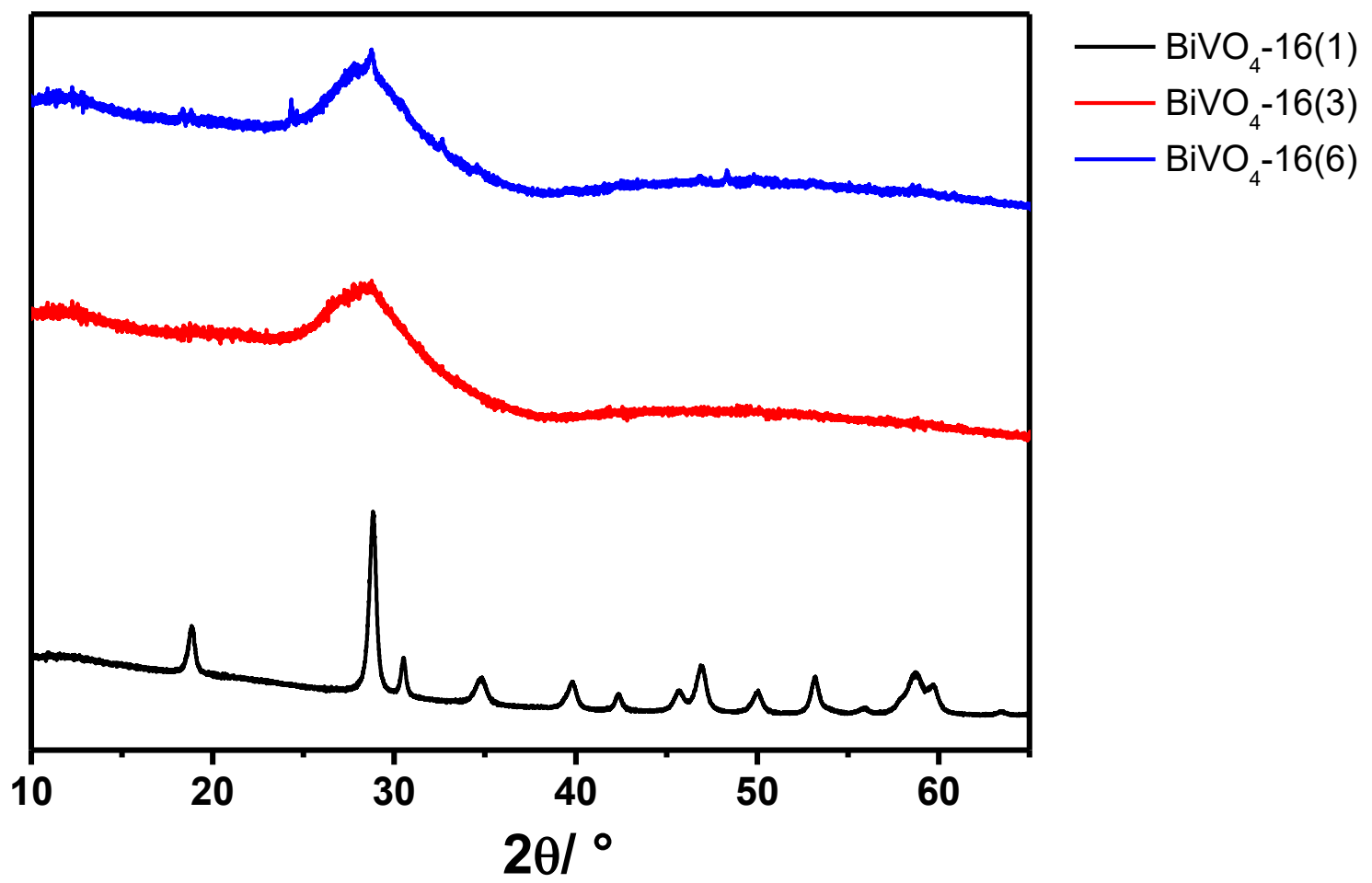

Figure S49. XRD diffractograms of $\mathrm{BiVO}_{4}-16(1), \mathrm{BiVO}_{4}-16(3)$ and $\mathrm{BiVO}_{4}-16(6)$. 


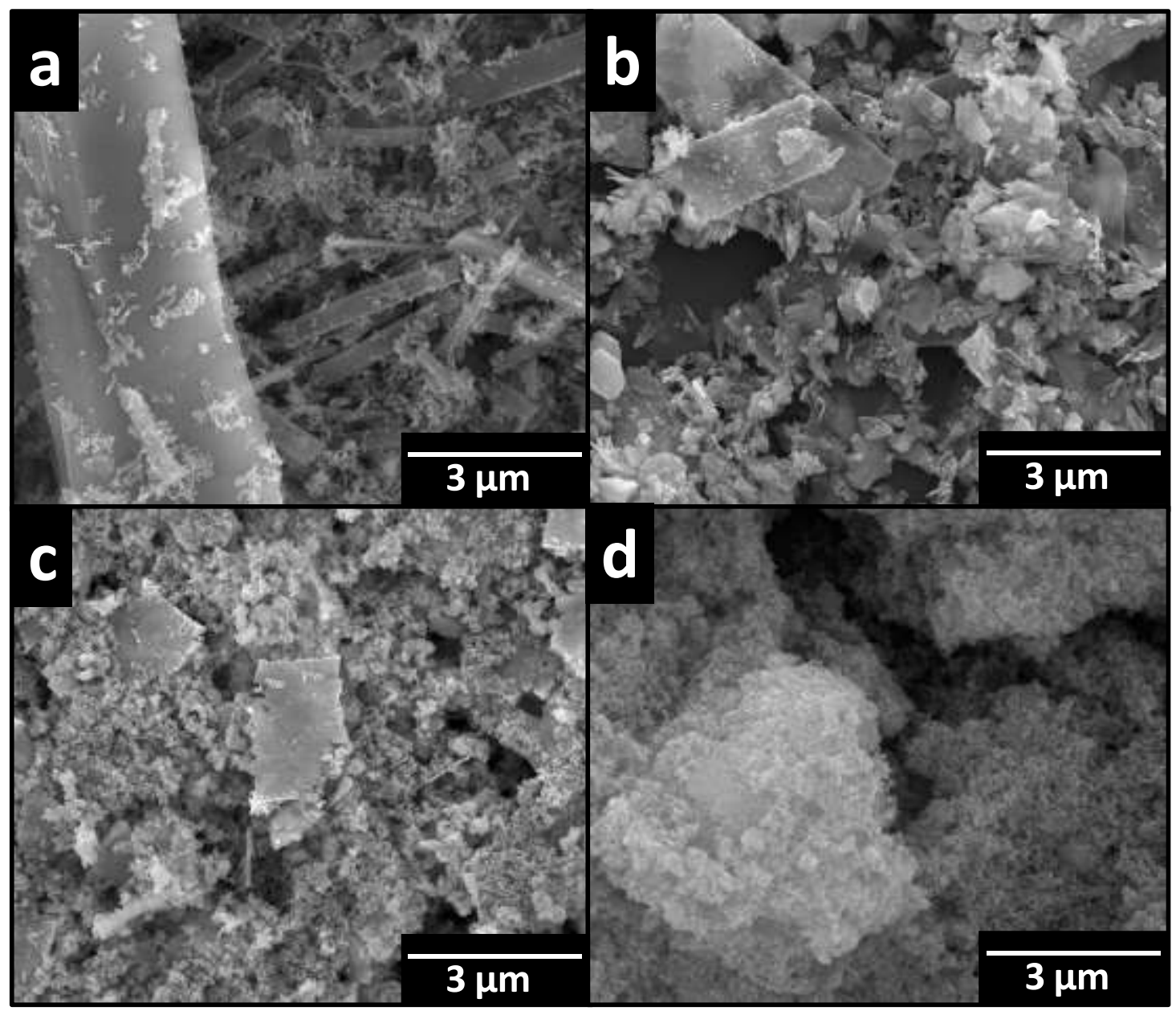

Figure S50. Scanning Electron Microscopy images of $\mathrm{BiVO}_{4}-2(6)(\mathrm{a}), \mathrm{BiVO}_{4}-6(6)$ (b), $\mathrm{BiVO}_{4}-10(6)$ (c) and $\mathrm{BiVO}_{4}-14(6)$ (d) samples. 


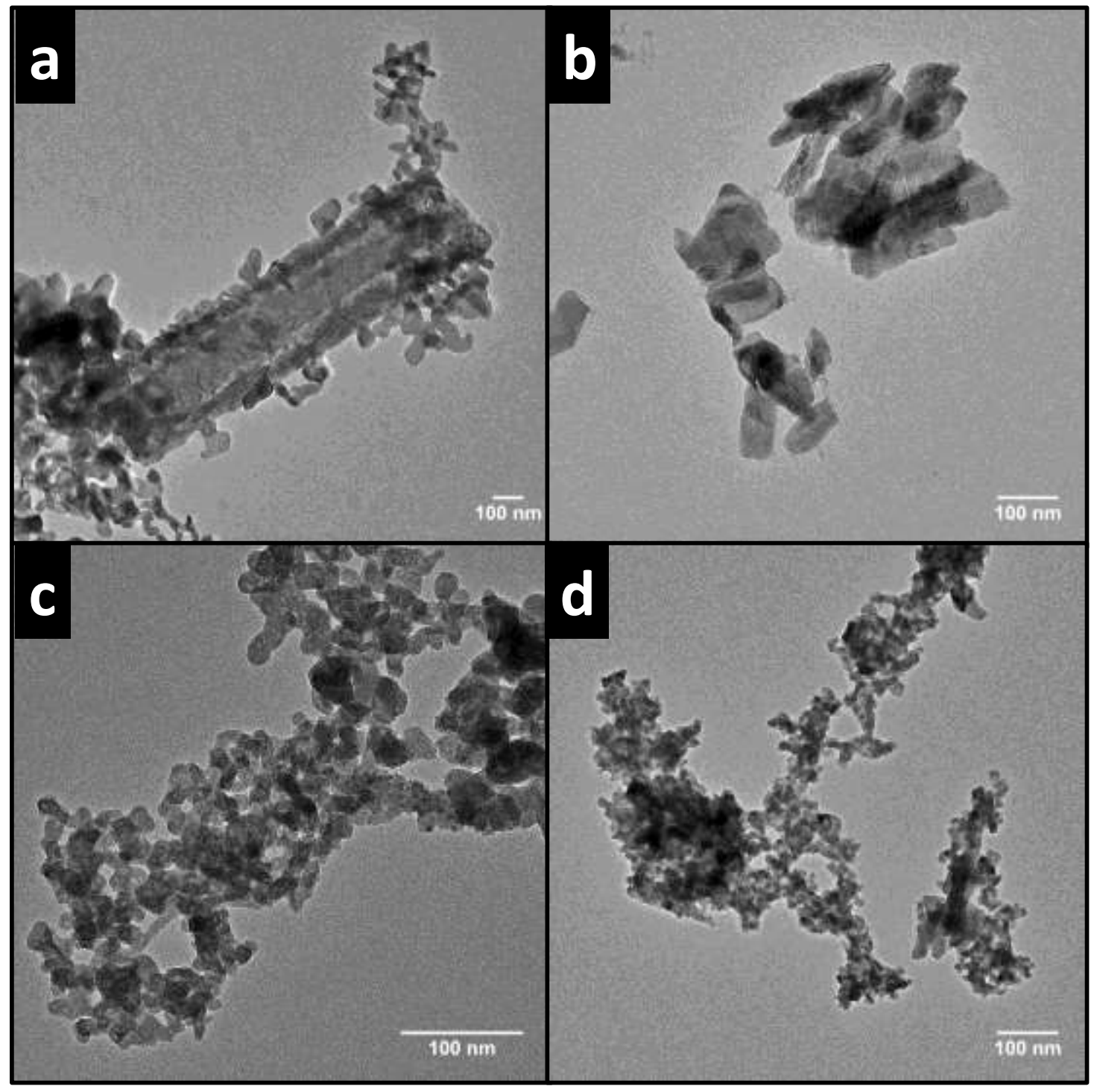

Figure S51. Transmission Electron Microscopy images of $\mathrm{BiVO}_{4}-2(6)(a), \mathrm{BiVO}_{4}-6(6)$ (b), $\mathrm{BiVO}_{4}-10(6)$ (c) and $\mathrm{BiVO}_{4}-14(6)$ (d) samples. 


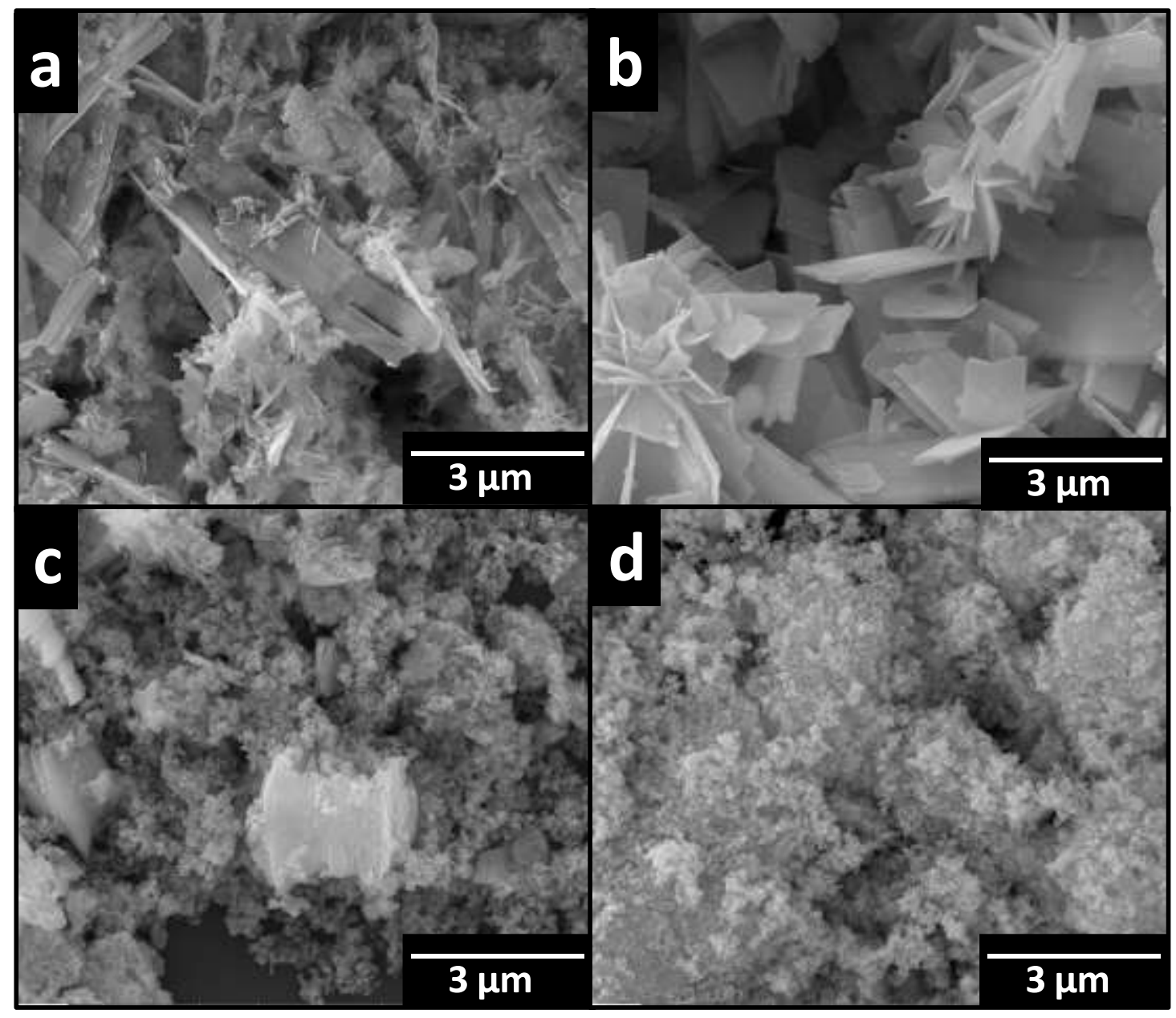

Figure S52. Scanning Electron Microscopy images of $\mathrm{BiVO}_{4}-3(6)(\mathrm{a}), \mathrm{BiVO}_{4}-7(6)$ (b), $\mathrm{BiVO}_{4}-11(6)$ (c) and $\mathrm{BiVO}_{4}-15(6)$ (d) samples. 


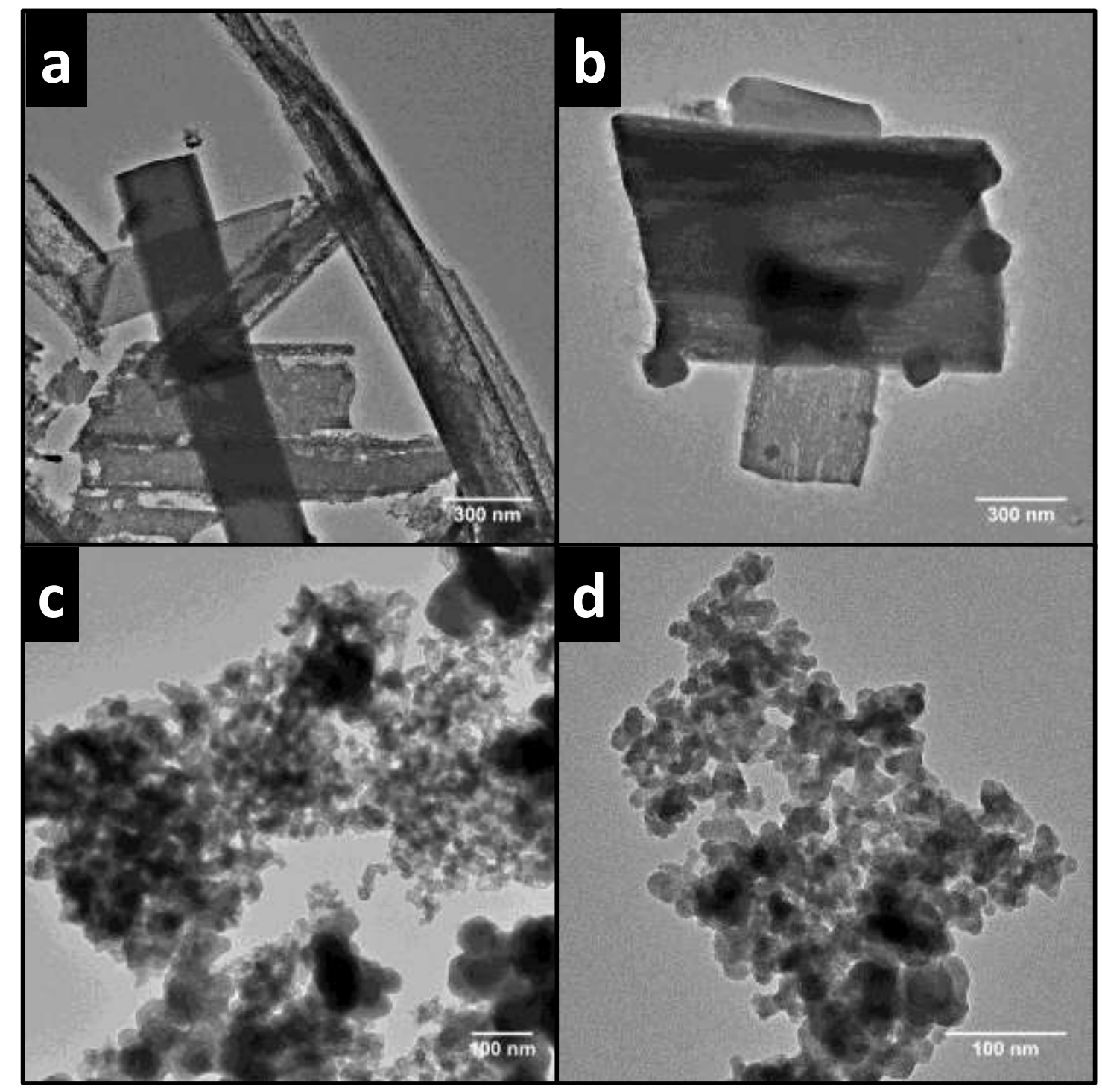

Figure S53. Transmission Electron Microscopy images of $\mathrm{BiVO}_{4}-3(6)$ (a), $\mathrm{BiVO}_{4}-7(6)$ (b), BiVO $_{4}-11(6)$ (c) and $\mathrm{BiVO}_{4}-15$ (6) (d) samples. 


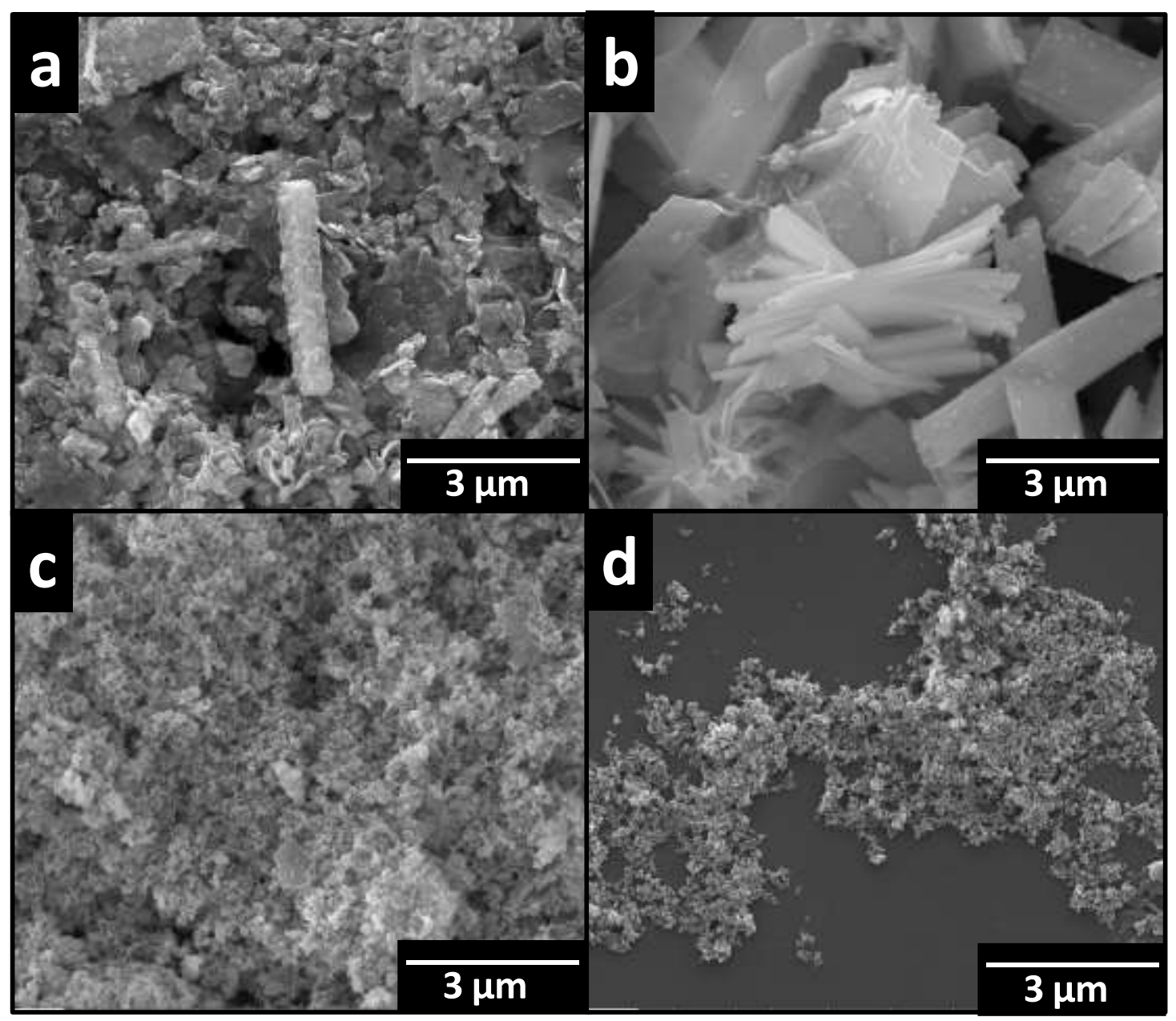

Figure S54. Scanning Electron Microscopy images of $\mathrm{BiVO}_{4}-4(6)(\mathrm{a}), \mathrm{BiVO}_{4}-8(6)$ (b), $\mathrm{BiVO}_{4}-12(6)$ (c) and $\mathrm{BiVO}_{4}-16(6)$ (d) samples. 


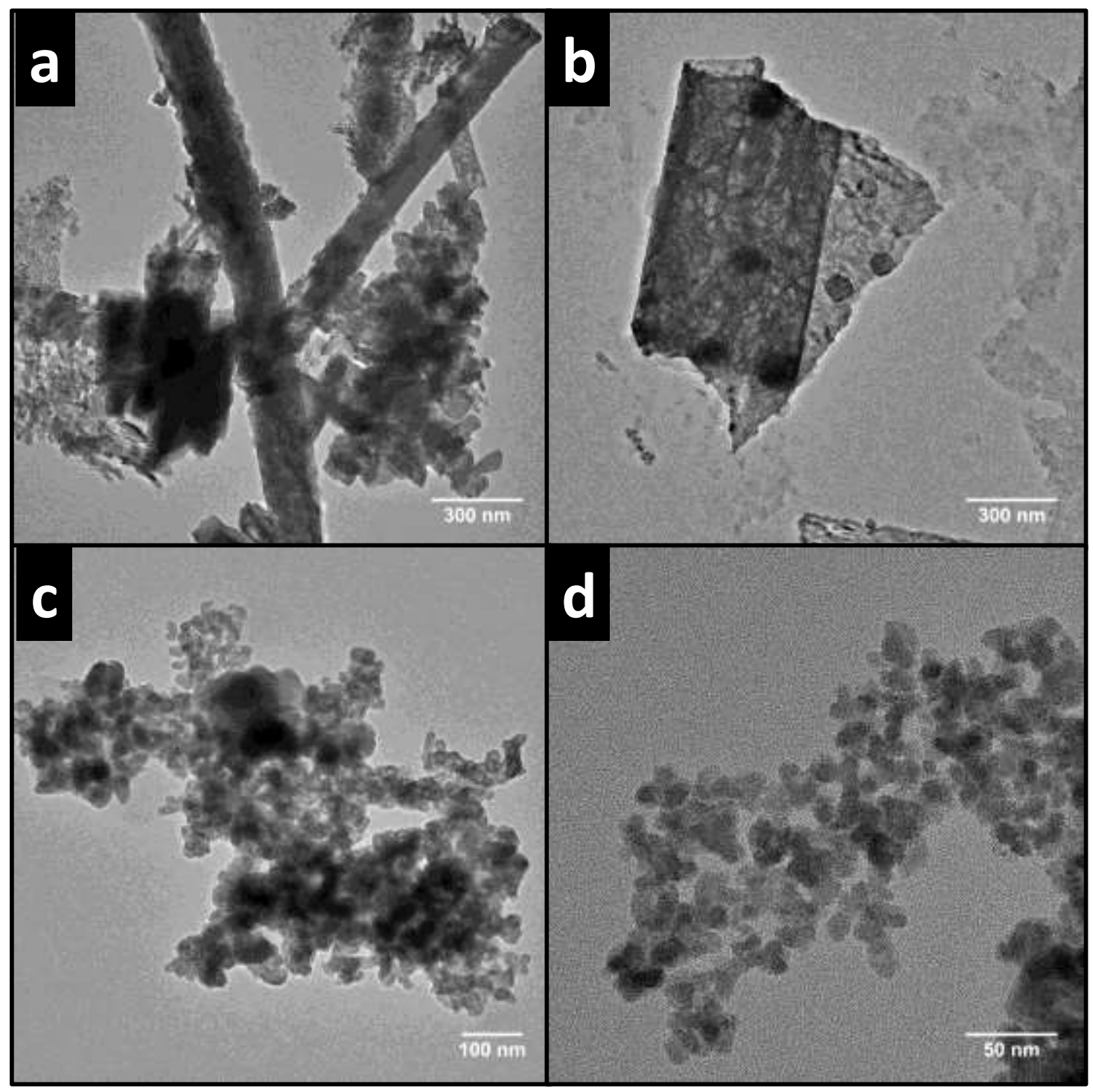

Figure S55. Transmission Electron Microscopy images of $\mathrm{BiVO}_{4}-4(6)(a), \mathrm{BiVO}_{4}-8(6)$ (b), $\mathrm{BiVO}_{4}-12(6)$ (c) and $\mathrm{BiVO}_{4}-16(6)$ (d) samples. 

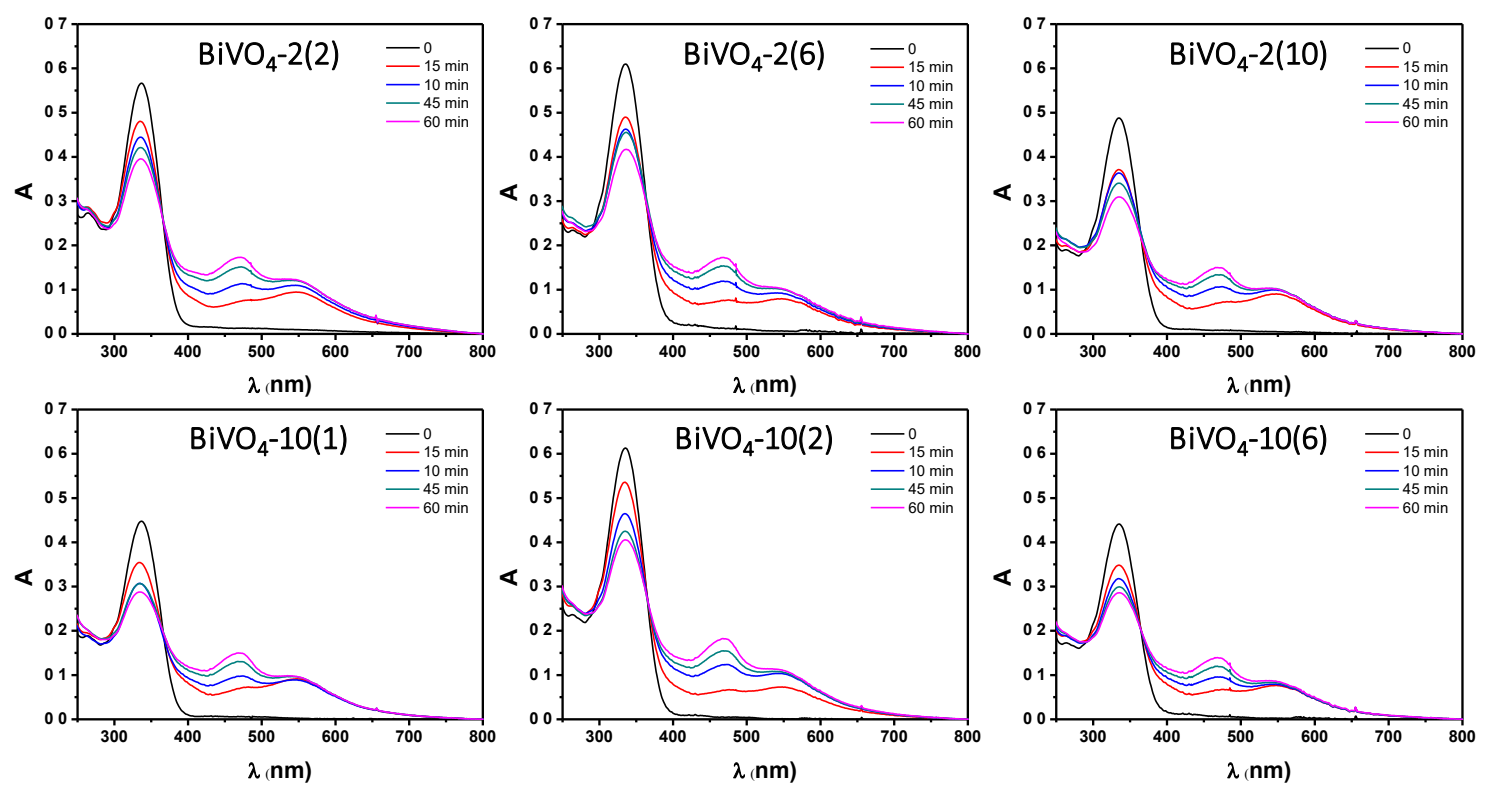

Figure S56. Electronic spectra of the adduct produced by the reaction of photogenerated $\mathrm{O}_{2} \cdot$ radical with NBD-Cl as a function of simulated sunlight irradiation time. 